\title{
The Potential Use of Cannabis in Tissue Fibrosis
}

\author{
Nazar Pryimak, Mariia Zaiachuk, Olga Kovalchuk* and Igor Kovalchuk* \\ Department of Biological Sciences, University of Lethbridge, Lethbridge, AB, Canada
}

Fibrosis is a condition characterized by thickening or/and scarring of various tissues. Fibrosis may develop in almost all tissues and organs, and it may be one of the leading causes of morbidity and mortality. It provokes excessive scarring that excels the usual wound healing response to trauma in numerous organs. Currently, very little can be done to prevent tissue fibrosis, and it is almost impossible to reverse it. Antiinflammatory and immunosuppressive drugs are among the few treatments that may be efficient in preventing fibrosis. Numerous publications suggest that cannabinoids and extracts of Cannabis sativa have potent anti-inflammatory and anti-fibrogenic properties.

OPEN ACCESS

Edited by: Susanne Sattler, Imperial College London, United Kingdom

Reviewed by:

Selvi Enrico,

Siena University Hospital, Italy Elaine Cristina Dalazen Gonçalves, Federal University of Santa Catarina,

Brazil

${ }^{*}$ Correspondence: Olga Kovalchuk olga.kovalchuk@uleth.ca Igor Kovalchuk

igor.kovalchuk@uleth.ca

Specialty section:

This article was submitted to Molecular and Cellular Pathology, a section of the journal Frontiers in Cell and Developmental Biology

Received: 26 May 2021 Accepted: 06 September 2021 Published: 11 October 2021

Citation:

Pryimak N, Zaiachuk M, Kovalchuk O and Kovalchuk I (2021) The Potential Use of Cannabis in Tissue Fibrosis. Front. Cell Dev. Biol. 9:715380. doi: 10.3389/fcell.2021.715380 In this review, we describe the types and mechanisms of fibrosis in various tissues and discuss various strategies for prevention and dealing with tissue fibrosis. We further introduce cannabinoids and their potential for the prevention and treatment of fibrosis, and therefore for extending healthy lifespan.

Keywords: fibrosis, anti-fibrotic, Cannabis sativa, cannabinoids, inflammation

\section{INTRODUCTION}

Fibrosis is a pathology associated with the replacement of parenchyma with connective tissue during the healing process. Fibrosis is defined as an excessive growth, stiffness, and sometimes scarring of different tissues or organs along with an imputed overaccumulation of extracellular matrix (ECM) components and collagen (Liu, 2011). Fibrotic illness is not well understood, it has a poor outcome and is mainly untreatable, all of which is compared to the terminal stage of cancer (Wernig et al., 2017). This condition is a lifelong pathological anomaly that may occur in various organs (Table 1), with a higher frequency in the skin, liver, heart, kidneys, and lungs.

Different types of fibrosis have been recognized based on anatomical location such as pulmonary [idiopathic pulmonary fibrosis (IPF), cystic fibrosis, emphysema], liver (cirrhosis, portal hypertension, hepatocellular carcinoma) or skin (keloids, systemic sclerosis). The most wellknown and studied example of fibrosis is IPF. This condition is a lifelong, incurable illness targeting lungs. This disease usually affects middle-aged people and older adults and is characterized by a long-lasting cough along with difficulties in breathing of an unknown origin; besides IPF is very difficult to diagnose. Many IPF patients struggle with an acute worsening of breathing that is correlated with high mortality. The progression rate of this condition is very unpredictable. Some patients can deteriorate very quickly, while others may remain asymptomatic for many years. There is no generally approved treatment for this disease. The development of treatments is focused on fibroproliferation and fibrogenesis (Liu, 2011; Fujimoto et al., 2015; Hoyer et al., 2019). Because of insensitivity to pharmacological treatments, an average survival time is 3 years.

Epidemiological data on fibrosis in different organs is well documented in the literature. For example, an incidence of IPF varies between 0.6 and 17.4 per 100,000 population per year 
TABLE 1 | Main types of fibrosis.

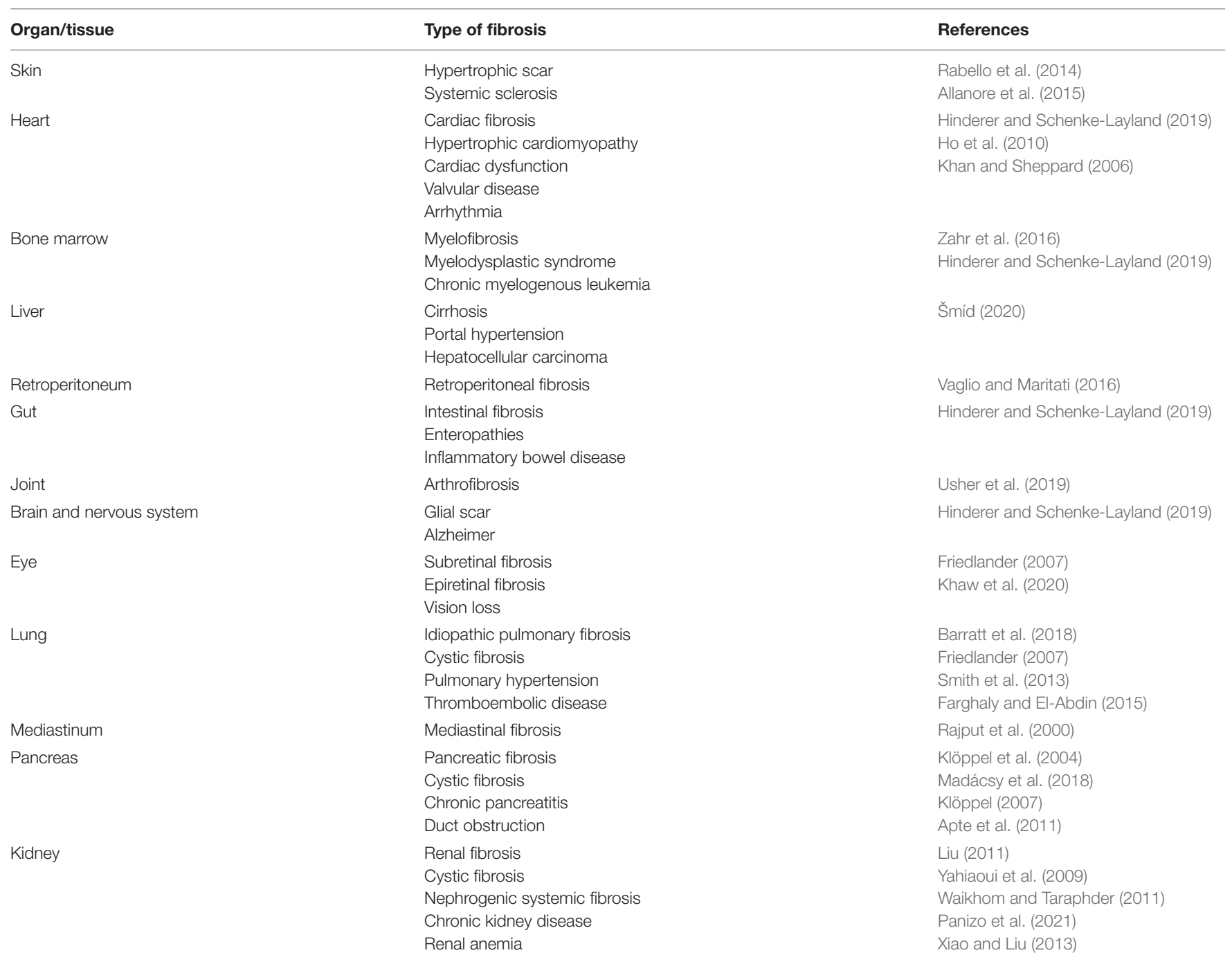

(Ley and Collard, 2013), two third of all patients were 60 years and above, and the highest prevalence was reported among patients of 80 years and above - 165.9 per 100,000 population (Raimundo et al., 2016). In Caucasians, cystic fibrosis occurs roughly in 1 in 3,000-4,000 births; and among other races, cystic fibrosis is less frequent, 1 in 4,000-10,000 in Latin Americans and 1 in 15,000-20,000 in African Americans, and even less in Asian Americans (Sanders and Fink, 2016). As to liver cirrhosis, according to 2017 data, 112 million compensated cases were reported worldwide (Sepanlou, 2020), and in patient who were more than 65 years old, a risk of severe liver fibrosis was 3.78 times higher (Kim et al., 2015). Also, more than 100 million cases of keloid are reported annually worldwide (Gauglitz et al., 2011; Li et al., 2017).

There is generally no good treatment of fibrosis and complete recovery is nearly impossible. Treatment includes various antiinflammatory and anti-fibrotic agents with various degree of success. In this respect, cannabinoids and Cannabis sativa extracts, known for their strong anti-inflammatory potential, may be serve as useful additives to treatment of fibrosis. In this review, we will cover the pathology of fibrosis and current therapy of fibrosis as well as introduce basic components of endocannabinoid system (ECS) and propose potential use of cannabinoids for treatment of fibrosis.

\section{PHASES OF NORMAL WOUND HEALING AND FIBROSIS}

In most cases, fibrosis occurs after acute or more often chronic damage to tissues, followed by abnormal repair. There are two ways of repair of the injured tissues. The first one is the regeneration by the propagation of undamaged cells of parenchyma and the maturation of stem cells - normal wound healing process. The second one is scar tissue formation through the accumulation of connective tissues - tissue fibrosis. The regeneration is a possibility of damaged tissues to be repaired and their defective elements to be restored. Cells that remain 
undamaged are able to proliferate and maintain the structure of the tissue. In some cases, fibrosis may occur due to a critical tissue injury or as a result of the inability of injured tissue to accomplish the repair. Fibrosis occurs due to either a large amount of collagen deposition associated with the long-lasting inflammation or ischemic necrosis. Cell proliferation is handled by growth factors, although the central role is played by ECM and maturation of stem cells (Occleston et al., 2010).

Different types of cells, such as fibroblasts, vascular endothelial cells, and some fragments of injured tissues proliferate along with the repair of damaged tissues. In fibrosis and scarring, tissue repair is characterized by the proliferation of connective tissues rather than parenchymal tissues that happens upon normal regeneration (Galliot et al., 2017).

\section{Phases of Wound Healing}

Wound healing consists of four main phases, including hemostasis, inflammation, proliferation or granulation and remodeling or maturation, each phase lasting from days to months (Figure 1).

Abnormal wound healing resulting in scar formation also includes similar phases/steps, such as inflammation, cell proliferation, and remodeling, but is characterized by more extensive deposition of collagen, fibrin, fibronectin, etc. (Profyris et al., 2012).

\section{The First Phase - Hemostasis}

The most crucial step is not to restore a tissue but to stop bleeding from the injured place. Coagulation starts exactly after trauma and finishes within hours. Collagen assists this process in the damaged area. Hemostasis consists of two subphases, primary and secondary hemostasis. Primary hemostasis is the formation of a plug at the injured place where endothelial cells become exposed. In the secondary hemostasis, there are two main pathways of blood clotting: the extrinsic and the intrinsic pathways, and they come together in the common pathway. The extrinsic pathway is a primary stage in plasma mediated secondary hemostasis. Due to tissue damage, tissue factor (TF also known as platelet tissue factor or factor III) is released in the plasma, which results in binding of factor VIIa and calcium to boost the activation of factor $\mathrm{X}$ to $\mathrm{Xa}$ (Figure 2). The intrinsic pathway includes factors I (fibrinogen), II (prothrombin), IX (Christmas factor), X (Stuart-Prower factor), XI (Plasma thromboplastin), and XII (Hageman factor) (Robertson and Miller, 2018). The common pathway includes steps from the activation of factor $\mathrm{X}$ to the formation of active thrombin which brakes fibrin into a cross-linked complex.

\section{The Second Phase - Inflammation}

Inflammation plays a central role in normal wound healing and fibrosis. Tissue repair and regeneration also depend on the extent of injury and inflammation. When the injury is extensive in the presence of chronic inflammation, repair may predominate even when the damaged cells can regenerate.

In normal circumstances, the inflammatory microenvironment quickly handles the damaged particles or pathogens. The essential factors of inflammation and fibrogenesis are summarized below (Table 2; Newton and Dixit, 2012; Kendall and Feghali-Bostwick, 2014).

\section{The Third Phase - Proliferation and Granulation}

Cell proliferation is an essential component of tissue repair, wound healing and fibrogenesis. There are several types of cells, such as epithelial cells, endothelial cells, and fibroblasts that participate in fibrogenesis and normal process of healing of the wound.

Mesothelial cells originate from the embryonic mesoderm and play an essential role during trauma or infection. For instance, in pleural injuries, they assist in transporting white cells. Also, as a result of mesothelial-to-mesenchymal transition (MMT), these cells, might be genetically reprogrammed after the influence of specific stimuli. In a recent mouse model, the lineage analysis of stem cells demonstrated that MMT increased the proliferation of myofibroblasts and hepatic satellite cells during liver fibrogenesis (Tirado and Koss, 2018).

Fibrocytes are of a mesenchymal origin and are phenotypically inactive due to a low amount of rough endoplasmic reticulum. These cells produce fibroblastic components such as collagen, fibronectin, and vimentin. When influenced by TGF- $\beta$, they can produce alpha-smooth muscle actin ( $\alpha$-SMA) which plays a role in angiogenesis and immunity. Fibrocytes can also migrate to the damaged area with blood flow (de Oliveira and Wilson, 2020).

Fibroblasts originate from the embryonic mesoderm tissues. Due to the chemotaxis feature, fibroblasts are able to migrate within tissue in response to chemical stimuli. In case of injury, they can cause contraction of the matrix that leads to the sealing of the open wound. Fibroblasts play an important role in fibrogenesis, for example, TGF- $\beta 1$ dependent differentiation into myofibroblasts (Weiskirchen et al., 2019).

Epithelial cells are located in different areas of the body, such as skin, urinary tract, blood vessels, and internal organs. One of the critical features is their ability to differentiate into different types of cells. During epithelial-to-mesenchymal transition (EMT), epithelial cells become transited cells that become sensitive to the fibroblast's specific protein (FSP1). The plasticity of epithelial cells allows them to become a source of myofibroblasts in the damaged cells (Macara et al., 2014).

Endothelial cells are mainly responsible for the formation of a barrier in the endothelium of capillaries, venules, vein, arterioles, and arteries. Being stimulated by TGF- $\beta$, endothelial cells can release $\alpha$-SMA and become able to convert into mesenchymal cells (endothelial-to-mesenchymal-transition, EndMT). It was demonstrated that EndMT could lead to fibrosis in the organs such as heart, kidney, and lungs (Sakai and Tager, 2013).

Pericytes are fibroblast-like cells that surround endothelial cells in blood vessels. Pericytes are able to contract and consequently control blood flow. In the case study, it was suggested that this type of cells produce $\alpha-S M A$, neural/glial antigen (NG2) and platelet-derived growth factor receptor$\beta$ (PDGFR- $\beta$ ). Moreover, they are a source of myofibroblasts in pulmonary tissues. Another study reported that Foxd1 progenitor-derived pericytes prominently lead to the lung fibrosis (Sakai and Tager, 2013). 


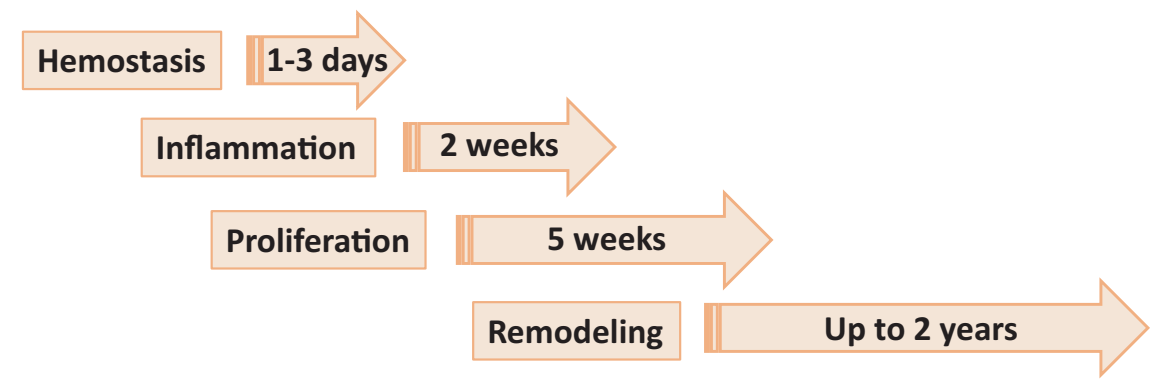

FIGURE 1 | Phases of wound healing. Phase 1, hemostasis is the process of clot formation to stop bleeding, and includes steps such as vasoconstriction, aggregation of platelets and migration of leukocytes. Phase 2, inflammation is the process of cleaning the wound and preparing for the formation of new blood vessels. It includes processes such as release of antibacterial molecules by neutrophils, engulfing of pathogens and debris by macrophages, and release of angiogenic substances to stimulation angiogenesis and granulation. Phase 3, proliferation (or granulation) - the process allowing to bring the wound edges together and seal it. It includes proliferation of the wound by fibroblasts, with secretion of glycoproteins and collagen, followed by migration of epithelial cells from the wound edges and formulation of granulation tissues. Phase 4, remodeling (or maturation) phase is mostly a continuation of proliferation phase resulting in formation of proper tissue.

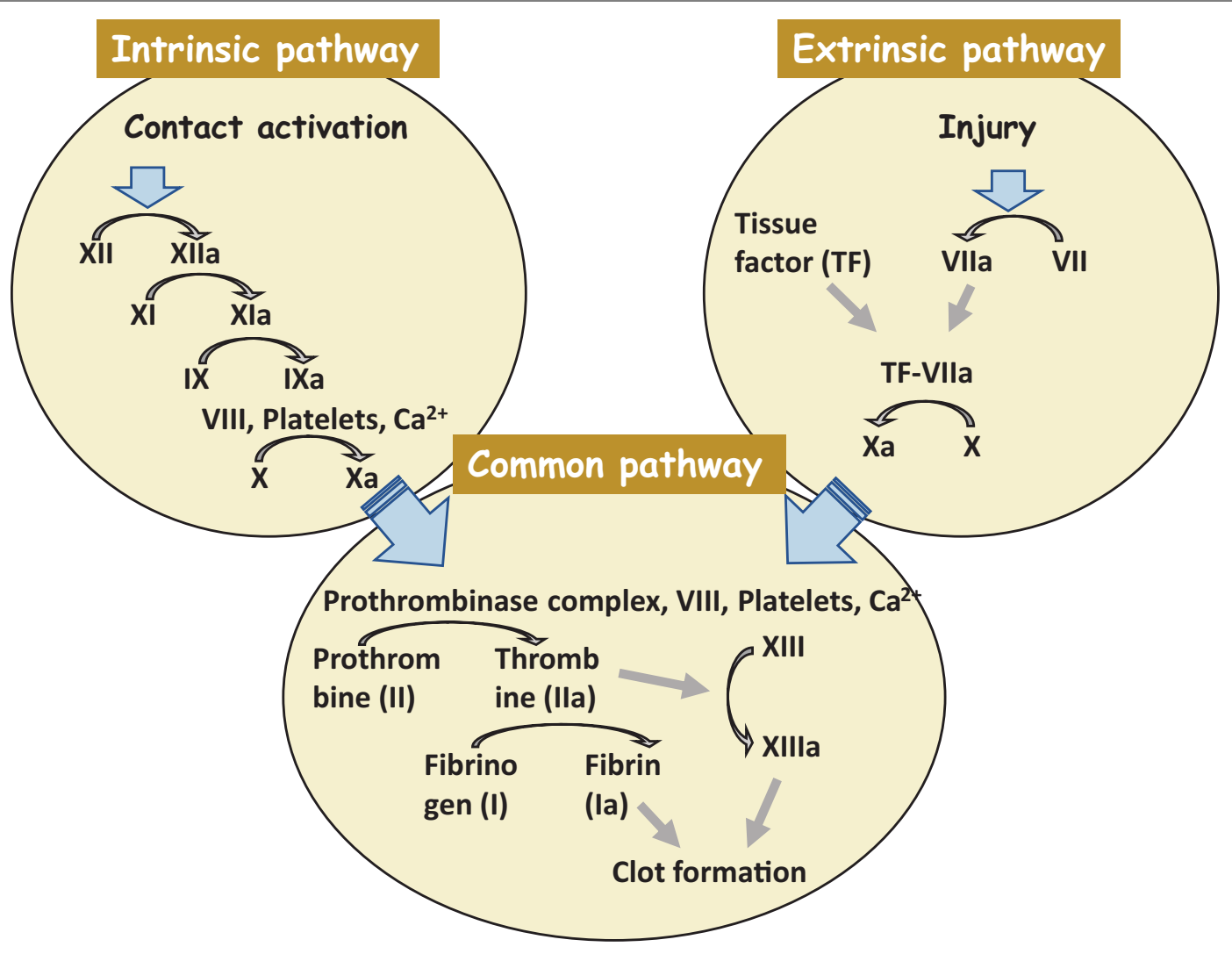

FIGURE 2 | A clot formation cascade. There are three steps of the clotting (coagulation) cascade: the intrinsic pathway (factors XII, XI, IX, and VIII), the extrinsic pathway (factor VII), and the common pathway. During clotting, cascade factor X may be activated by the extrinsic and intrinsic pathways. The common pathway consist of steps from the activation of factor X to the clot formation. Factors that are activated are shown with a lowercase "a".

Vascular smooth muscle cells are responsible for the relaxation and contraction of blood vessels. As a result of the injury, they produce $\alpha$-SMA, vimentin, desmin, and other compounds. It has also been shown that collagen type $\mathrm{I}$ is induced by bradykinin secretion in vascular smooth muscle cells through the TGF- $\beta 1$ activation (Liu et al., 2017).
There are two main processes involved in proliferation phase of repair: formation of granulation tissues and wound contraction. Wound contraction usually starts on day 2-3 and is finished within 2 weeks. The primary cells that are responsible for this process are myofibroblasts, the unique cells that have features of fibroblasts and smooth muscle. The main role of these cells is 
TABLE 2 | Key mediators of inflammation and fibrogenesis.

\begin{tabular}{|c|c|c|c|c|}
\hline & Substance & Production site & Effects & References \\
\hline \multirow[t]{9}{*}{$\begin{array}{l}\text { Profibrotic } \\
\text { factors acting } \\
\text { on fibroblasts }\end{array}$} & $\mathrm{TGF} \beta$ & White blood cells & $\begin{array}{l}\text { Transformation of resident (subcutaneous, pulmonary, etc.) } \\
\text { fibroblasts to myofibroblasts. } \\
\text { Stimulation of collagen and fibronectin transcription. } \\
\text { Stimulation of resting monocytes and inhibition of activated } \\
\text { macrophages. }\end{array}$ & Frangogiannis (2020) \\
\hline & $\|-1 \beta$ & Fibroblasts, macrophages & $\begin{array}{l}\text { Inflammation promotion and fibrotic responses (in part, through } \\
\text { activation of } \mathrm{TNF} \alpha \text { ). }\end{array}$ & $\begin{array}{l}\text { Lopez-Castejon and } \\
\text { Brough (2011) }\end{array}$ \\
\hline & IL-6 & $\begin{array}{l}\text { T cells, skeletal muscle cells, } \\
\text { macrophages }\end{array}$ & $\begin{array}{l}\text { Regulation of inflammation (pro- and anti-inflammatory). } \\
\text { Stimulation of cellular differentiation and fibrosis. }\end{array}$ & Tanaka et al. (2014) \\
\hline & $\| \mathrm{L}-13$ & $\begin{array}{l}\text { Mast cells, T lymphocytes, } \\
\text { eosinophils and basophils }\end{array}$ & $\begin{array}{l}\text { Stimulation of TGF } \beta \text { production, proliferation of fibroblasts, } \\
\text { collagen and MMP production. }\end{array}$ & Marone et al. (2019) \\
\hline & IL-33 & $\begin{array}{l}\text { Smooth muscle cells, epithelial } \\
\text { and endothelial cells }\end{array}$ & $\begin{array}{l}\text { Signals through ST2 to initiate and enhances profibrogenic } \\
\text { cytokine production in a macrophage-dependent manner. }\end{array}$ & Li et al. (2014) \\
\hline & $\mathrm{TNF} \alpha$ & $\begin{array}{l}\text { Macrophages, T lymphocytes, } \\
\text { NK cells, mast cells, eosinophils }\end{array}$ & $\begin{array}{l}\text { Stimulation of inflammation and fibrosis, in part through TGF- } \beta \\
\text { signaling pathway, activation of myofibroblasts and increased } \\
\text { secretion of MMPs. }\end{array}$ & Yoshimatsu et al. (2020) \\
\hline & FGFs & Various parenchymal cells & $\begin{array}{l}\text { Fibrosis enhancement through binding and activation of } \\
\text { fibroblast growth factor receptor (FGFR). }\end{array}$ & Xie et al. (2020) \\
\hline & PDGF & $\begin{array}{l}\text { Platelets, smooth muscle cells, } \\
\text { endothelial cells and } \\
\text { macrophages }\end{array}$ & $\begin{array}{l}\text { Stimulation differentiation, proliferation, and ECM production via } \\
\text { interaction with PDGF } \alpha \text { and PDGF } \beta \text { receptors on } \\
\text { myofibroblasts. }\end{array}$ & $\begin{array}{l}\text { Klinkhammer et al. } \\
\text { (2018) }\end{array}$ \\
\hline & $\begin{array}{l}\text { Leukotrienes } \\
\text { (LTB4, LTC4, } \\
\text { LTD4, LTE4) }\end{array}$ & White blood cells & $\begin{array}{l}\text { Stimulation of fibroblasts proliferation and production of the } \\
\text { matrix via modulation of the production of cyclic AMP by } \\
\text { interaction with G-protein adenylate cyclase. }\end{array}$ & $\begin{array}{l}\text { Kowal-Bielecka et al. } \\
(2007)\end{array}$ \\
\hline \multirow[t]{8}{*}{$\begin{array}{l}\text { Profibrotic } \\
\text { factors released } \\
\text { from fibroblasts }\end{array}$} & VEGF & $\begin{array}{l}\text { Macrophages, fibroblasts, } \\
\text { platelets }\end{array}$ & $\begin{array}{l}\text { Angiogenesis promotion. } \\
\text { Facilitates monocyte recruitment and infiltration of fibrotic } \\
\text { tissues mediated through a VEGF-dependent sinusoidal } \\
\text { permeability, leading either to resolution or promotion of fibrosis. }\end{array}$ & Yang et al. (2014) \\
\hline & $\|-1$ & Fibroblasts & $\begin{array}{l}\text { Facilitates inflammation and fibrosis through autocrine } \\
\text { stimulation of IL-1 receptor. }\end{array}$ & Kelly et al. (2019) \\
\hline & IL-6 & Fibroblasts & $\begin{array}{l}\text { Facilitation of inflammation and fibrosis through binding of IL-6 } \\
\text { to IL-6R } \alpha \text { receptor, which then associates with the } \\
\text { signal-transducing gp130 protein to facilitate phosphorylation of } \\
\text { the transcription factor STAT-3. Phosphorylated STAT-3 } \\
\text { regulates expression of pro-fibrotic genes. }\end{array}$ & Kobayashi et al. (2015) \\
\hline & IL-33 & Dermal and cardiac fibroblasts & $\begin{array}{l}\text { Promotion of inflammation and fibrosis by signaling through ST2 } \\
\text { and activating TGF } \beta \text { production. }\end{array}$ & Kotsiou et al. (2018) \\
\hline & Angiotensin ॥ & $\begin{array}{l}\text { Macrophages and } \\
\text { myofibroblasts }\end{array}$ & $\begin{array}{l}\text { Promotion of TGF } \beta \text { mediated heart remodeling. Fibrosis } \\
\text { enhancement via the angiotensin type } 1 \text { receptor (AT1). }\end{array}$ & Rosenkranz (2004) \\
\hline & $|G F| \mid$ & Fibroblasts & $\begin{array}{l}\text { Stimulation of fibrosis through } \\
\text { mannose-6-phosphate/insulin-like growth factor receptor } \\
\text { (M6P/IGFII receptor) in turn activating latent transforming } \\
\text { growth factor } \beta \text { (L-TGF- } \beta \text { ). }\end{array}$ & Ghahary et al. (2000) \\
\hline & IGFBP-3 & & $\begin{array}{l}\text { Fibrosis initiation and enhancement by binding IGF-I and ECM } \\
\text { components, inducing the production of extracellular matrix } \\
\text { components such as collagen type I and fibronectin. Inhibit IGF } \\
\text { mediated proliferation (via MEK/ERK and PI3K/AKT). }\end{array}$ & Pilewski et al. (2005) \\
\hline & IGFBP-5 & & & Yasuoka et al. (2009) \\
\hline \multirow[t]{3}{*}{$\begin{array}{l}\text { Antifibrotic } \\
\text { factors acting } \\
\text { on fibroblasts }\end{array}$} & $\mathrm{PGE}_{2}$ & Almost all nucleated cells & $\begin{array}{l}\text { Inhibition of fibroblast proliferation and suppression of collagen } \\
\text { production. Promotion of normal fibroblast apoptosis through } \\
\text { EP2/EP4 signaling and a reduction in the Akt activity. }\end{array}$ & Huang et al. (2009) \\
\hline & HGF & Fibroblast & $\begin{array}{l}\text { Prevents fibrosis and induces tissue repair acting through Met } \\
\text { receptor and supporting the growth in epithelial and endothelial } \\
\text { cells, but not in myofibroblasts. }\end{array}$ & $\begin{array}{l}\text { Panganiban and Day } \\
\text { (2011) }\end{array}$ \\
\hline & PPAR ligands & Expressed in almost all tissues & $\begin{array}{l}\text { Potent antifibrotic effects, reduction of } \beta \text {-catenin levels. } \\
\text { Regulate the fate determination of mesenchymal cell lineage. }\end{array}$ & $\begin{array}{l}\text { Jeon et al. (2017) } \\
\text { Vallée et al. (2017) }\end{array}$ \\
\hline
\end{tabular}

the contraction of the wound by up to $80 \%$. Granulation tissue is soft in touch and has a pink color. Granulation is a sign of tissue repair; it is formed by three steps: the inflammatory phase, the clearance phase, and the ingrowth of granulation tissue (Figure 3). During the inflammation phase, cells that are predominantly involved in the process are monocytes and 
neutrophils. The clearance phase is characterized by the release of autolytic enzymes from dying cells as well as enzymes from neutrophils; macrophages also clear necrotic debris. The final phase is the ingrowth of granulation tissue during which granulation tissue is formed. This phase can be divided into two processes: angiogenesis and fibrogenesis (Baum and Duffy, 2011; Bochaton-Piallat et al., 2016; Alhajj et al., 2020).

Angiogenesis (neovascularization) is the development of blood vessels. Angiogenesis could be the result of sprouting either from pre-existing blood vessels or from stem cells. There are a few steps in the angiogenesis from pre-existing blood vessels. The first one involves vessel dilation that is mediated by NO, and the second step includes an increased vascular permeability that is mediated by the vascular endothelial growth factor (VEGF). The next step is a breakdown of the basement membrane and the formation of a vessel sprout. The other step is the migration of endothelial cells toward chemotactic and angiogenic stimuli that cause a proliferation of endothelial cells and their maturation leading to capillary tube remodeling. The final phase of angiogenesis is the accumulation of periendothelial cells (pericyte) (Papetti and Herman, 2002).

Angiogenesis from stem cells develops from endothelial precursor cells (EPC) stored in the bone marrow, and if needed, they migrate to the place of injury (Aldair and Montani, 2010).

\section{The Fourth Phase - Healthy Remodeling or Remodeling With Fibrogenesis}

Remodeling (maturation phase) after injury usually takes place from several weeks to months or years and depends on what type of tissue is damaged, injury location, and the associated comorbidities (infections, arteriosclerosis, vein thrombosis, nutritional status, diabetes, and some drugs). During remodeling phase, rate of synthesis of collagen by fibroblasts exceeds the rate at which it is degraded, resulting in continuous increase in the amount of collagen. Remodeling includes three steps: functional recovery, wound contraction and an increased tensile strength of the wound (Cañedo-Dorantes and Cañedo-Ayala, 2019). The maturation phase is characterized by the formation of scar tissue as well as by the absence of inflammatory cells (neutrophils, macrophages) and the termination of blood vessel proliferation. Granulation tissue in the scar is replaced by dense collagen. The scar initially consists of a provisional matrix that contains fibrin, fibronectin, and collagen type III, but later on, collagen type III is replaced by collagen type I (Reinke and Sorg, 2012). The next step is wound contraction, with the main goal being a reduction of a gap between two cut margins. Myofibroblasts play a key role during this phase. Figure 4 shows all major processes of differentiation, activation or transition of various cells into myofibroblasts. Collagen type I is responsible for the last step an increase in the strength of the wound. The recovery of $~ 80 \%$ of the original tissue strength will usually take up to 3 months.

Skin wound healing can be subdivided into primary and secondary unions (Alhajj et al., 2020). By primary union (first intention), regeneration occurs with a minimum scaring tissue, for example, a clean surgical wound. By secondary union (secondary intention), the wound has the larger tissue defects with a wide distance between edges; wound healing by secondary intention occurs by regeneration and scarring. In some cases, due to abnormal wound healing, keloids or hypertrophic scars might occur. In a hypertrophic scar, there is a build-up of extra collagen fibers, which results in the elevation of the scar. Fibrillar collagen fibers are located parallel to the epidermis with a lumpy red scar, and they do not extend beyond the original scarring area. Usually, hypertrophic scars affect younger individuals with the delayed healing of wounds caused by underlying conditions such as infections, and usually, there is an improvement with the treatment. Morphologically keloids are characterized as eosinophilic, focally fragmented complexes of haphazardly arranged collagen. Also, in comparison with hypertrophic scars, one-third of keloids have $\alpha$-SMA- expressing myofibroblasts. The scar tissue in keloids grows beyond the inflammation area, and it is difficult to treat (Moshref et al., 2010).

\section{Physiological Injury Healing vs. Pathological Fibrosis}

Fibrosis of the organ tissues is caused by parenchymal cell destruction (alteration or injury phase); as a result of tissue trauma, macrophages become active and enter the damaged area. Also, local immune cells create chemokines and cytokines which activate mesenchymal cells located close to the injury area. The next step is the initiation of the production of ECM and the elevated manufacturing of pro-inflammatory cytokines and angiogenic factors (Weiskirchen et al., 2019). After trauma, cells produce inflammatory mediators that provoke the antifibrinolytic coagulation cascade, the first step of which is the coagulation. During this stage, known as inflammation stage, platelets are activated and form fibrin clots. Next, platelets liberate inflammatory chemokines. Then the infiltration of leukocytes happens into the injured site, and they excrete profibrotic cytokines (TGF- $\beta$ and IL-13). Neutrophils are typically engaged in the infiltration process earlier than lymphocytes and macrophages (Rosales, 2018).

The proliferation stage follows the inflammation stage; during this stage, fibroblasts become active, and myofibroblasts induce and deposit ECM that will be a framework through the tissue regeneration action. The last step is remodeling (Gonzalez et al., 2016). In physiological recovery, the extra volume of ECM is degraded, myofibroblasts and fibroblasts go through apoptosis, and inflammatory cells leave the recovered tissues. On the other hand, the fibrosis process extends inflammation, and myofibroblasts stimulate the elevated accumulation of ECM which leads to the creation of a perpetual fibrotic scar. The contrasting features that distinguish fibrosis from normal wound healing are chronic inflammation, the persistence of myofibroblast activity, MMP-TIMP imbalance, and the excessive ECM deposition. These differences are very important to be understood from the therapeutic point of view because drugs can be prescribed to target these particular molecular disturbances.

Fibroblasts control synthesis and catabolism of collagen as well as an increase in collagen amount by MMPs and their inhibitors (tissue inhibitors of TIMPs). Changing the balance between these mechanisms will cause the elevation or dropping of collagen amount inside the injured area. In addition, an 


\section{Phases of proliferation}
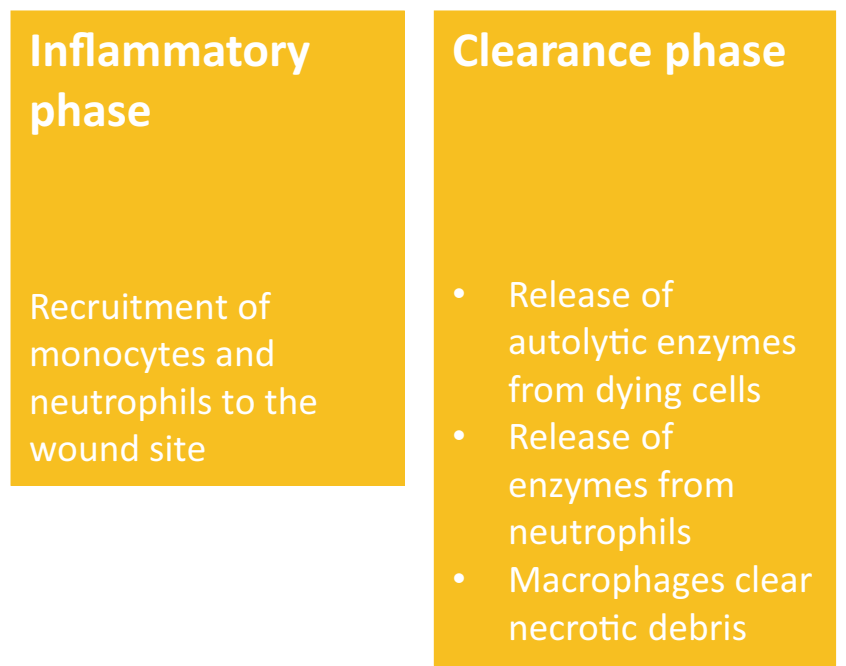

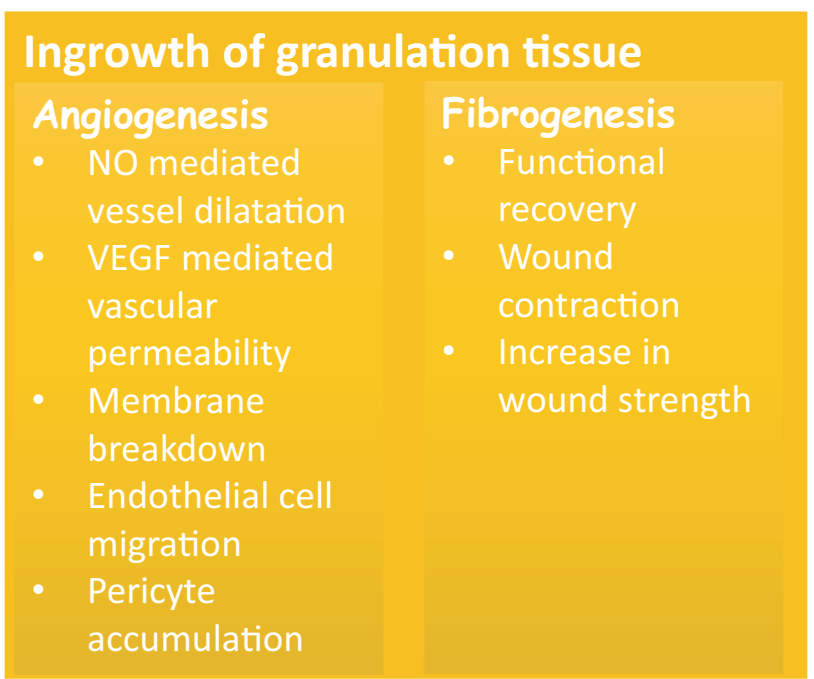

FIGURE 3 | Phases of proliferation and granulation.

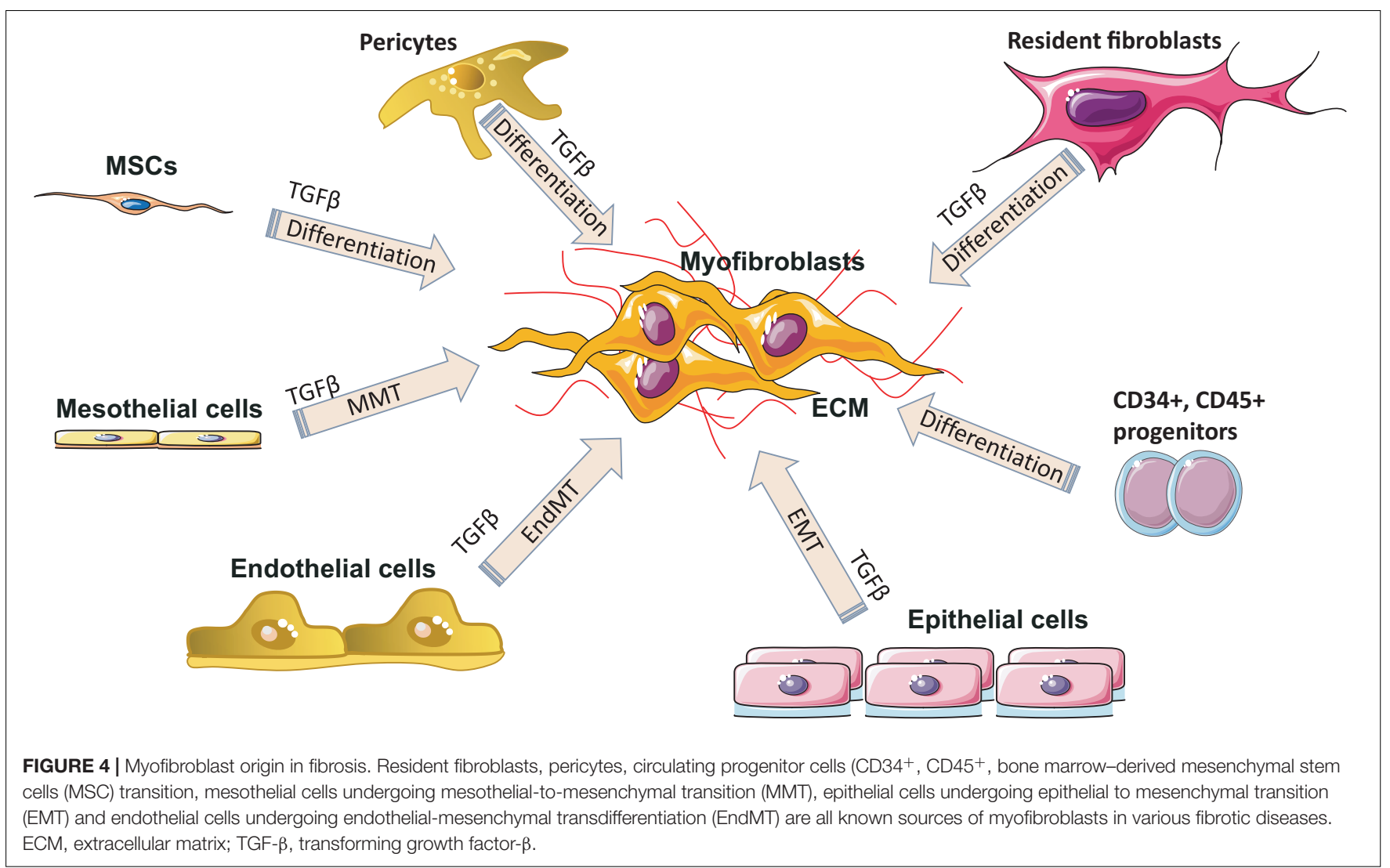

increasing number of mesenchymal cells will aggravate response. During the remodeling phase, fibroblasts synthesize collagen at a higher rate than they degrade it, leading to the continuous accumulation of collagen. Generally, inflammation stimulates fibrosis. According to some reports, however, fibrosis is not always driven by inflammation. This fact clarifies the shortage 
of efficacy of anti-inflammatory mediators in the management of the fibrotic disease (Wynn, 2007; Kryczka and Boncela, 2015).

\section{Fibrosis Prevention and Treatment Options}

Prevention strategies for the development of fibrosis are very important in the modern world because life expectancy and the patients' quality of life are expected to rise gradually. When patients are aware of avoidable risk factors for this condition, they, for example, should quit smoking to prevent the development of pulmonary fibrosis and should treat all acute diseases in time to prevent the development of chronic conditions. There are unavoidable factors such as genetics, the existing comorbidities (diabetes mellitus, herpes virus infection), the environmental exposures, air pollution as well as chronic use of some medications that also have to be considered (Zaman and Lee, 2018).

Anti-inflammatory drugs are widely used to manage fibrosis due to a strong connection between inflammation and fibrosis (Suthahar et al., 2017; Lands and Stanojevic, 2019; Simon et al., 2019). As a result of better understanding of the pathology of fibrosis, molecular targets of this condition and modern drugs affecting it have been recently discovered. A single-component medication is characterized by the presence of a single component that can target either extracellular or intracellular factors. The main extracellular targets are MMPs, growth factors, TNF. Most of the drugs targeting intracellular factors are small molecules; they can easily translocate inside the cytoplasm compared to other large molecules, like monoclonal antibodies.

There are four categories of intracellular factors that can be targeted by anti-fibrotic medicine: nuclear receptors, enzymes, other proteins, and epigenetic factors ( $\mathrm{Li}$ et al., 2017). The antifibrotic medications suppress kinases located in the cytoplasm, and moreover, they inhibit the translocation of transcription factors responsible for the expression of profibrotic genes.

Epigenetic regulators represent a very specific category of anti-fibrotic treatment. The main targets of epigenetic-based management of fibrosis are microRNAs (miRNAs). Anti-miRs are miRNA oligonucleotides that are able to complementary bind to miRNAs involved in fibrosis and neutralize them when deposited inside the cell. miRNAs like let-7, miR-21, miR-29, miR-155 play an important role in fibrosis, particularly in TGF$\beta$ control. Let-7 and miR-29 are antifibrotic; in contrast, miR-21 and miR-155 are profibrotic, and their expression will rise during the fibrosis. On the other hand, the decreased expression of miR29 in systemic sclerosis (SSc) fibroblasts leads to the increased levels of type I and III collagen. The reduction of miR-29 was noted in the fibrotic reaction in the lungs, heart, and kidneys. IL-4, TGF- $\beta$, and PDGF-B reduced the level of miR-29 in SSc fibroblasts as well as in the bleomycin-induced model of skin fibrosis (Maurer et al., 2010; Harmanci et al., 2017). According to another study, miR-21 was highly elevated in animal and human models of transplant kidney nephropathy. MiR-21-/mice experienced less interstitial fibrosis in response to kidney injury; this was pheno-copied in wild-type mice that were treated with anti-miR-21 oligonucleotides. The peroxisome proliferatoractivated receptors (Ppar $\alpha$ ) and Mpv17l are two main metabolic pathways that are key targets for miR-21. Also, miR-21 downregulated inhibitors of angiogenesis and migration, especially the RECK (the reversion-inducing cysteine-rich protein with Kazal motifs) and the atypical matrix metalloproteinase (MMP) inhibitor that led to the enhanced MMP activity in kidney injury (Chau et al., 2012). As a result of the administration of oligonucleotides that silenced miR-21, a reversal of the deleterious action of miR-21 in kidney injury was noted. Some studies demonstrated a significant effect of miR-21 on pulmonary and cardiac fibrosis (Thum et al., 2008).

In multi-component therapy, several approaches are combined, with numerous ingredients acting on numerous targets. In fibrosis, there are multiple pathological pathways and multi-component drugs that are able to modulate these pathways and create synergistic effects. In the Table 3 , single and multi-component medications used nowadays in the treatment of fibrosis are summarized (Li et al., 2017).

Only nintedanib and pirfenidone have been approved by FDA for the treatment of fibrosis, particularly of IPF, and ruxolitinib has been approved by FDA for the treatment of myelofibrosis; other medications are still experimental, and some of them are undergoing clinical trials the results of which might help improve the understanding of the fibrosis pathway.

Nintedanib medication is a small molecule kinase inhibitor that reduces the proliferation and migration of lung fibroblasts. Nintedanib inhibits receptor tyrosine kinases (RTKs), for instance, FGFR1-3, VEGFR1-3, Fns-like tyrosine kinase-3 (FLT3), PDGFR $\alpha$ and $\beta$. Also, this drug inhibits kinase signaling pathways. Its main side effects are nausea, diarrhea, and liver dysfunction (Wind et al., 2019; Valenzuela et al., 2020). In clinical practice, a long-term use of nintedanib is still discussed. Research in this area will help improve patient outcomes (Valenzuela et al., 2020). Pirfenidone treatment mainly reduces fibroblast proliferation and causes the inhibition of collagen synthesis and down-regulation of profibrotic cytokines. As a result of inhibition, it causes the suppression of TGF$\beta 2$ mRNA levels and TGF- $\beta 2$ protein and the suppressed expression of the TGF- $\beta$ pro-protein convertase furin. Also, this drug decreases the MMP-11 protein levels. It should be noted that pirfenidone has some severe side effects such as photosensitivity, nausea, stomach pain and many others that may lead to medication intolerance and discontinuation (Hughes et al., 2016; Margaritopoulos et al., 2016; Moran-Mendoza et al., 2019). Ruxolitinib is widely used in myelofibrosis treatment. This drug is a kinase inhibitor that is selective for JAK1 and 2. The main role of these kinases is the regulation of growth factor signaling and cytokine release. The known side effects of this medicine are anemia, thrombocytopenia, increased liver enzymes, and diarrhea (Elli et al., 2019).

\section{The Role of Cannabinoids and Cannabis in Inflammation and Fibrosis}

Recently, the ECS has received a significant attention from mainstream medical professionals, being viewed as an important 
TABLE 3 | Single- and multi-component medications targeting fibrosis factors.

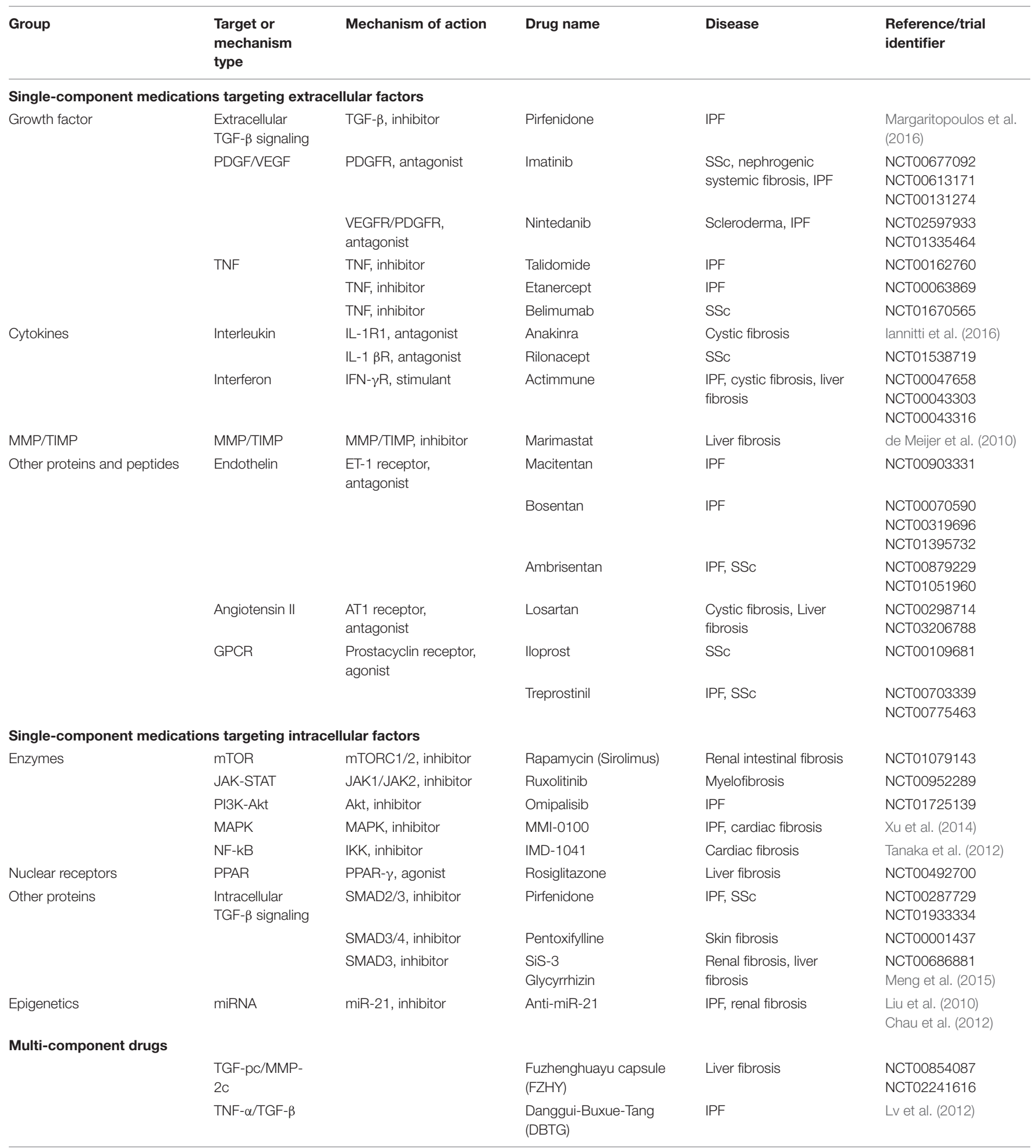

TGF- $\beta$, transforming growth factor- $\beta$; PDGF, platelet-derived growth factor; PDGFR, platelet-derived growth factor receptor; VEGF, vascular endothelial growth factor; VEGFR, vascular endothelial growth factor receptor; TNF, tumor necrosis factor; IFN- $\gamma R$, interferon- $\gamma$ receptor; MMP, matrix metalloproteinase; TIMP, tissue inhibitor of metalloproteinase; ET-1 receptor, endothelin-1 receptor; AT1 receptor, angiotensin II receptor type 1; GPCR, G protein-coupled receptor; mTOR, mechanistic target of rapamycin; mTORC1, mechanistic target of rapamycin complex 1; JAK-STAT, janus kinase/signal transducers and activators of transcriptions; PI3K-Akt, phosphoinositide 3-kinase/protein kinase B; MAPK, mitogen-activated protein kinase; NF-kB, nuclear factor kappa-light-chain- enhancer of activated B cells; IKK, I-kappa B kinase; SMAD3, mothers against decapentaplegic homolog 3. 
therapeutic target for many pathological conditions. Human physiology significantly depends on a proper function of this system. The ECS has been established as an important homeostatic regulator. It affects almost all functions of the body. It consists of endocannabinoids (2-AG, AEA), their metabolic enzymes and receptors, including cannabinoid receptors 1 (CB1), cannabinoid 2 (CB2), transient receptor potential channels of the vanilloid subtype 1 and 2 (TRPV1, TRPV2), G protein-coupled receptors 18, 55, 119 (GPR18, GPR55, GPR119) (Laezza et al., 2020). Cannabinoid receptors are highly expressed in cells involved in two subtypes of immunity, adaptive and innate. For example, CB1 and CB2 receptors are expressed in the natural killer cells, macrophages, $\mathrm{T}$ and $\mathrm{B}$ cells (Chiurchiù, 2016). In general, activation of the CB2 receptor leads to anti-inflammatory effects. Since the expression of $\mathrm{CB} 1$ receptors is lower in the immune cells than the expression of $\mathrm{CB} 2$ receptors, their function in the immune system still remains controversial (Turcotte et al., 2016). $\mathrm{CB}^{-/-}$mice exhibit abnormalities in the development of $\mathrm{T}$ and B cells (Ziring et al., 2006). Cannabinoids, mainly by modulating the expression of ECS receptors induce apoptosis of immune cells, and inhibit their proliferation; suppress proinflammatory cytokines production, and induce T-regulatory cells (Nagarkatti et al., 2009). The imbalance in the ECS can significantly impact the proper functioning of the whole organism, including fibrosis and inflammation processes. For example, the activation of the $\mathrm{CB} 1$ receptor leads to fibrogenesis, while the enhancement of the CB2 receptor inhibits fibrosis progression (Mallat et al., 2011). In animal models, it was demonstrated that the deletion of CB1 caused an improvement of liver fibrosis, whereas CB2 deletion resulted in an elevated amount of collagen accumulation and an increased inflammation (Patsenker and Stickel, 2016). Concerning inflammation, the use of CB2 receptor agonists was documented to inhibit the infiltration of inflammatory cells into liver tissue. In addition, CB2 receptor knockout mice had the more profound inflammation and damage to the liver than wild-type mice (Batkai et al., 2007).

Cannabis is widely known as a plant with psychoactive properties. It includes over 500 compounds such as different cannabinoids, terpenes, terpenoids, fatty acids, and flavonoids. Cannabinoids (known as phytocannabinoids in contrast to endocannabinoids) act via the ECS. The most abundant are cannabidiol (CBD) and $\Delta 9$-tetrahydrocannabinol ( $\triangle 9$-THC); they are the most studied cannabinoids with numerous documented medicinal properties (Zurier and Burstein, 2016; Lafaye et al., 2017). The uniqueness of the effect of cannabis extracts is in entourage effect. Often, but not always, cannabis extracts have more profound effects on various disease and conditions than isolated cannabinoids (Kovalchuk and Kovalchuk, 2020). This is due to modifying effects of minor cannabinoids, terpenes and other molecules that frequently act as amplifiers, acting on the same receptors. Looking at the enormous varieties of cannabis cultivars nowadays, it is clear that research in this field should continue to discover new possibilities of fibrosis treatment (Russo, 2019).

\section{Cannabinoids as Anti-inflammatory Agents}

According to previous reports, some of the cannabinoids can be used as anti-inflammatory agents (Zurier and Burstein, 2016; Wang et al., 2020). Currently in medical practice, these substances have little documented negative effect on patients in comparison with other drugs. Cannabinoids have other mechanisms of action on inflammation in comparison with nonsteroidal anti-inflammatory drugs (NSAIDs). NSAIDs inhibit the activity of cyclooxygenase enzymes, prostaglandins (Zurier and Burstein, 2016). Recently, it has been discovered that cannabinoid receptor signaling regulates the proliferation and function of fibroblasts which are crucial cells in scar formation (Nagarkatti et al., 2009). By suppressing inflammation, they may stop the progression of repair by scarring. It has been shown that cannabinoids and cannabis extracts suppress the pro-inflammatory cytokines IL- 2 , IL- $1 \beta$, TNF- $\alpha$, IFN- $\gamma$, IL-12, IL-8, IL-6 in different cell lines and animal models. Due to this, the inflammatory process will be prominently inhibited (Nagarkatti et al., 2009).

One of the anti-inflammatory mechanisms of cannabinoids is through the regulation of mitochondrial homeostasis. CBD has been shown to alleviate cerebral ischemia in rats by reducing brain oedema, blood-brain barrier permeability, infarction size, and neurological deficit. This effect was due to the increased expression of $\mathrm{Na}^{+} / \mathrm{Ca}^{2+}$ exchanger proteins (Khaksar and Bigdeli, 2017). When blood flow is restored in the ischemic area, it causes inflammation and oxidative-stress-related injury in the affected area. CBD has demonstrated a neuroprotective effect in oxygen-glucose-deprivation/reperfusion in vitro model by reducing the oxidative stress, improving mitochondrial bioenergetics and modulating the glucose metabolism (Sun et al., 2017). In contrast, THC treatment of the trophoblast cell line, HTR8/SVneo, showed a reduction in mitochondrial respiratory function and membrane potential. This data suggested that THC can cause dysfunction of mitochondria (Walker et al., 2021). When THC effect was evaluated on mitochondria, extracted from the rat brain, similar results were obtained: it enhanced oxidative stress and induced mitochondrial dysfunction in the brain (Wolff et al., 2015).

Cannabis extracts were even proposed to be used for prevention and treatment of COVID-19. Significant inhibitory effects on the key receptor protein Ace2 required for SARS-Cov2 virus entry in the gateway entry tissues was found in response to several cannabis extracts (Wang et al., 2020). Similarly, several other extracts were found to be potent inhibitors of major pro-inflammatory molecules responsible for severe COVID-19 progression (Wang et al., 2020).

It was also shown that cannabis users living with HIV have lower neuroinflammation. This was confirmed by demonstrating that marijuana users had lower levels of CD16+ monocytes and inducible protein 10 (IP-10) compared to HIV-infected patients non-cannabis users (Rizzo et al., 2018).

\section{Cannabinoids as Anti-fibrotic Agents}

A lot of research has already been done, and currently many studies are undergoing on the use of endo-, synthetic, and phytocannabinoids in the fibrosis field. In one in vivo study 
where a mouse model of type I cardiomyopathy was used, it was demonstrated that CBD treatment diminished the diabetesassociated cardiac fibrosis. A significant decrease of collagen deposition and the expression of profibrotic genes like MMP2, MMP-9, TGF- $\beta$, connective tissue growth factor, fibronectin andcollagen-1 were noted (Montecucco and Di Marzo, 2012).

Liver fibrosis is a usual complication of many long-lasting liver illnesses such as viral hepatitis B and C, non-alcoholic steatohepatitis, drug-induced liver injury, alcohol abuse, and autoimmune conditions. In long-lasting liver damage, the activated hepatic stellate cells (HSCs) and myofibroblasts are the main contributors to the development of liver cirrhosis and hepatocellular cancer ( $\mathrm{Fu}$ et al., 2011). An in vitro study performed on HSCs documented that CBD induced the programmed cell death of these cells (Lim et al., 2011). This effect was independent of cannabinoid receptors and was the result of endoplasmic reticulum stress induction. In addition, CBD enhanced the pro-apoptotic pathway IRE1/ASK1/c-Jun $\mathrm{N}$-terminal kinase, which resulted in HSCs death. This CBDinduced programmed cell death of activated HSCs was confirmed in vitro in human, mouse and rat cell lines, but not in the quiescent cell lines. The well-known fact that the activated HSCs play a crucial role in the development and continuation of liver fibrosis supports the fact that cannabis extracts might be turned into promising antifibrotic drugs as they lead to the selective apoptosis of activated HSCs. The results of this study are very encouraging for further investigation of CBD in vivo (Lim et al., 2011). In addition, a meta-analysis of nine studies performed on 5,976,026 patients concluded that marijuana did not elevate the prevalence or progression of liver fibrosis in patients with hepatitis C or hepatitis C HIV co-infection (Hosein Mohimani et al., 2017). Also, it was noted that marijuana users had a reduced prevalence of non-alcoholic fatty liver disease (NAFLD). Furthermore, these patients consumed more sodas and alcohol, therefore the healthy lifestyle was not a cause of the reduced prevalence of NAFLD. This effect might be induced by reducing fat depositions via omega-3 fatty acids and the impact of CBD on insulin sensitivity (Hosein Mohimani et al., 2017).

Concerning the effect of THC, it has been shown that it also inhibits the proliferation of liver myofibroblasts and stellate cells via $\mathrm{CB} 2$ receptors and leads to their programmed cell death. Due to this, THC may also possess antifibrotic properties (Tam et al., 2011).

The endocannabinoid AEA also demonstrated the antifibrogenic features by suppressing the proliferation of HSC and induction of necrosis. The elevated AEA levels were documented in cirrhotic patients, which might be a response to fibrosis. This endogenous cannabinoid can trigger the topical inflammatory response and systemic dilatation of vessels, therefore the opportunity for fibrosis treatment was restricted (Parfieniuk and Flisiak, 2008). Another endocannabinoid, 2-AG, was considered as a fibrogenic agent. When used in higher doses in vitro on HSC, it activated fibrosis via the membrane cholesterol-dependent mechanism (Tam et al., 2011). Another endogenous cannabinoid, oleoylethanolamide (OEA), was used in a mouse model of hepatic fibrosis and showed the inhibition of collagen deposition and suppression of collagen type I and III gene expression, $\alpha$-SMA,
MMP2, MMP9, and TIMP1. These effects were mediated through the PPAR $\alpha$ mechanisms (McVicker and Bennett, 2017).

Synthetic cannabinoids were also shown to be beneficial for fibrosis treatment. An in vitro study performed on pulmonary fibroblasts demonstrated that JWH133, a CB2 receptor agonist, suppressed the collagen type I and $\alpha$-SMA and inhibited the proliferation and migration of fibroblasts. These effects were reversed by the use of a CB2 receptor antagonist, SR144528. In vivo studies on bleomycin-induced lung fibrosis in mice, showed that JWH133 decreased the lung density, and the fibrotic score and histological results illustrated the suppression of the collagen accumulation and inflammatory response. In both models, this particular synthetic cannabinoid inhibited the crucial pathway of fibrogenesis, TGF- $\beta 1 / \mathrm{Smad} 2$ (Fu et al., 2017). WIN-55,212, a nonselective CB1 and CB2 receptor agonist as well as JWH133 were assessed on the mouse model of systemic sclerosis. They prevented the development of dermal and pulmonary fibrosis and inhibited the proliferation of fibroblasts. $\mathrm{CB} 2^{-/-}$mice developed a significantly enhanced skin and lung fibrosis compared with $\mathrm{CB} 2^{+/+}$mice, indicating significant influence of the $\mathrm{CB} 2$ receptor on fibrosis development (Servettaz et al., 2010). Rimonabant, a CB1 receptor antagonist, was assessed on rat models of liver cirrhosis induced by carbon tetrachloride. Fibrosis was prominently suppressed by the use of this synthetic cannabinoid in rats compared with rats in the vehicle group. Rimonabant downregulated the fibrogenic (TIMP-1, TGF- $\beta$, MMP13, MMP2, MMP9, MMP1, MMP8) and inflammatory mediator (TNF- $\alpha, \mathrm{MCP}-1)$ genes. In addition, Rimonabant treatment induced a prominent increase in the expression of the CB2 receptor (Giannone et al., 2012). Another study demonstrated that chronic stimulation of CB2 receptor with selective CB2 receptor agonist, JWH-133, leads to regression of fibrosis in cirrhotic rats. This selective agonist suppressed the inflammatory infiltrate, decreased fibrosis, lowered the number of activated hepatic stellate cells, and improved arterial pressure in comparison to the vehicle group. In addition, JWH-133 reduced levels of $\alpha$-SMA and collagen and elevated levels of MMP-2 in the liver tissue of rats with cirrhosis in comparison with untreated rats with cirrhosis. This data provided promising results for the possibility to use selective CB2 receptor agonists as a treatment modality of hepatic fibrosis in humans (Muñoz-Luque et al., 2008). Another study tested the effect of a selective CB2 receptor agonist, AM1241, on myocardial fibrosis post-myocardial infarction in mice. The echocardiography results demonstrated that AM1241 significantly enhanced cardiac function; downregulated expression of collagen I, collagen III, TIMP-1, and plasminogen activator inhibitor (PAI)-1. When primary cardiac fibroblasts were exposed to hypoxia and serum deprivation to simulate ischemia, AM1241 was able to reduce $\alpha$-SMA, collagen I and collagen III; this effect was partially abrogated by the Nrf2 siRNA transfection. Moreover, the CB2 receptor agonist, AM1241, activated and enhanced the translocation of Nrf2 to the nucleus and inhibited the TGF- $\beta 1 /$ SMAd 3 pathway. These data suggest that activation of the CB2 receptor might be one of the key targets to combat heart fibrosis after myocardial infarction (Li et al., 2016). The chronic peripheral pharmaceutical 
TABLE 4 | Anti-fibrotic effect of cannabinoids.

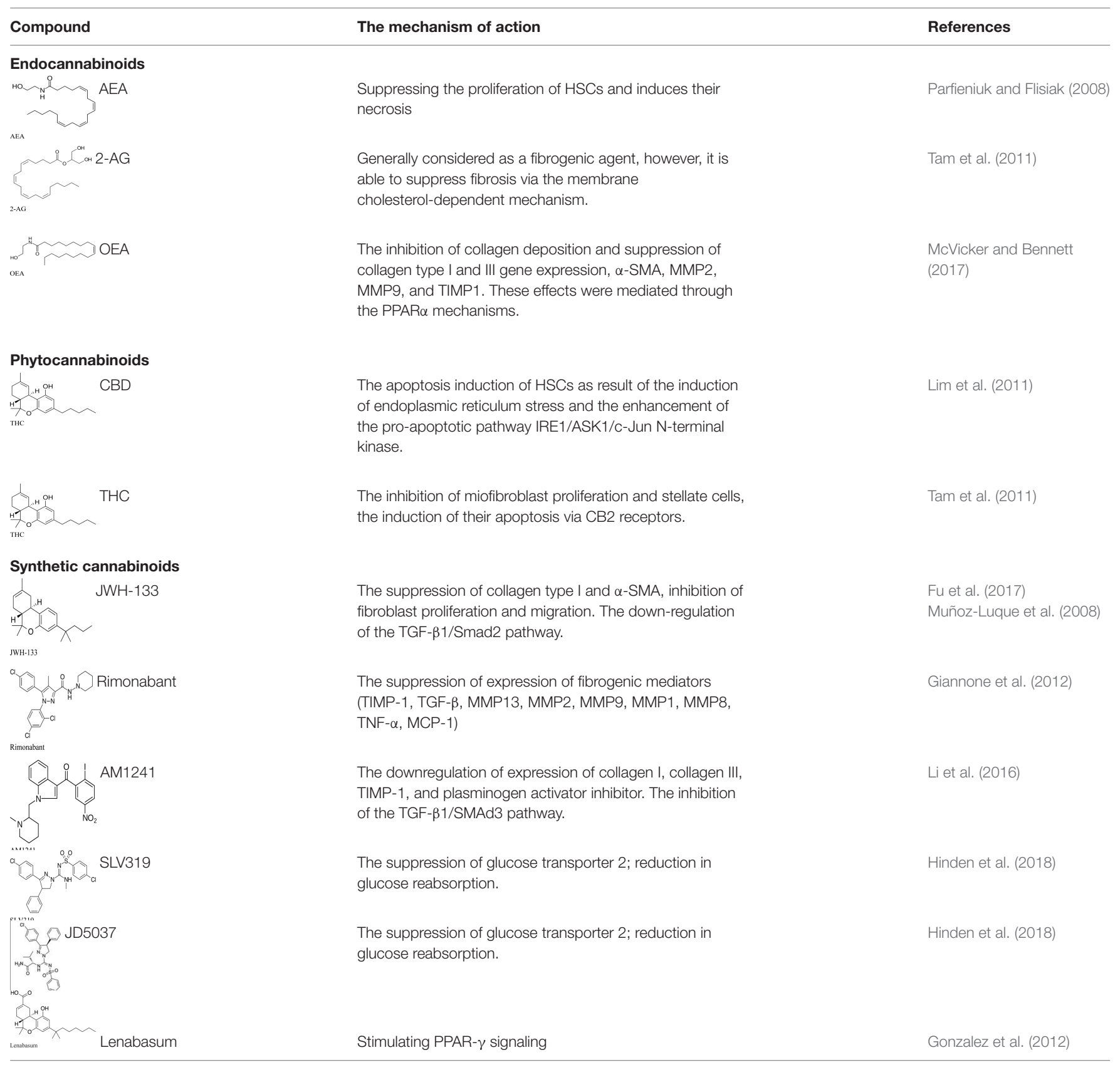

blockage of CB1 receptor (by SLV319 or JD5037 selective CB1 receptor antagonists) or genetic inactivation of $\mathrm{CB} 1$ receptors in the renal proximal tubule cells reduced kidney inflammation, suppressed tubulointerstitial fibrosis, and diminished diabeticinduced changes in the kidneys in mice. Also, the downregulation of the CB1 receptor suppressed glucose transporter 2, which resulted in reduced glucose reabsorption. These data supported the fact that peripheral CB1 receptor antagonists might be useful in treating patients with diabetic nephropathy (Hinden et al., 2018). A synthetic analog of THC, ajulemic acid (lenabasum), being a CB2 agonist, significantly prevented the development of bleomycin-induced skin fibrosis in mice and suppressed its progression. In addition, it inhibited collagen synthesis by skin fibroblasts obtained from patients with scleroderma. These effects were achieved by stimulating PPAR- $\gamma$ signaling (Gonzalez et al., 2012). Lenabasum has been shown to have an anti-inflammatory capacity by directly affecting both arachidonic acid pathways (Burstein, 2021). Lenabasum was the only synthetic cannabinoid studied in human fibrotic diseases. A Phase II, randomized, placebo-controlled trial in adults suffering from systemic sclerosis showed promising results (NCT03398837); a high improvement rate on the immunosuppressant therapy background, and high 
improvement on mycophenolate that has an anti-fibrotic activity and prevents pulmonary deterioration in pulmonary fibrosis was observed. Unfortunately, the primary endpoint was not met during this trial (Spiera et al., 2021). Table 3 summarizes type of cannabinoids and their mechanism of action (Table 4).

\section{Into Potential Mechanisms of Anti-fibrotic Effects of Cannabinoids - Role of MicroRNAs}

The mechanisms of anti-fibrotic effects of cannabinoids are likely very diverse. Cannabinoids may target all steps of normal and abnormal wound healing, as shown on Figure 5.

Recent reports demonstrate the role of miRNAs in regulation of cannabinoid receptors and anti-fibrotic effect of cannabinoids. miRNAs like miR-30b-5p, miR-21, miR-155, miR-146a, miR141, and miR-222 appear to be pro-inflammatory, while miRNAs like miR-187, miR-149, miR-145, and miR-99b are antiinflammatory.

miR-30b-5p was found to be involved in CB1-mediated NLRP3 inflammasome activation. The study performed on mice with liver injury induced by carbon tetrachloride $(\mathrm{CCl} 4)$ or methionine-choline-deficient, and high fat (MCDHF) diet showed that there is a relationship between $\mathrm{CB} 1$ receptor and Nod-like receptor family pyrin domain containing 3 (NLRP3) inflammasome in liver inflammation. The expression of the $\mathrm{CB} 1$ receptor was increased in hepatic tissue of mice with liver injury. CB1 receptor agonist, arachiodonyl-2'-chloroethylamide, enhanced expression of NLRP3 inflammasome and its activation in macrophages. AM281, a CB1 receptor antagonist, inhibited NLRP3 expression and activation of the inflammasome and reduced hepatic inflammation in CCl4- and MCDHF-treated mice. When miR-30b-5p agomir was administered, it targeted NLRP3 and mitigated liver inflammation. These results suggested that CB1/miR-30b-5p axis is able to modulate the activation of NLRP3 inflammasome and expression of NLRP3 in macrophages in liver inflammatory disease (Yang et al., 2020).

Cannabinoids can alter the expression of miR-155, a master regulator of inflammation (Mahesh and Biswas, 2019). Administration of selective CB2 receptor agonist AM1241 significantly reduced expression of TLR $4, \alpha-S M A$, TGF- $\beta 1$, miR-155, p65 NFkB, TNF- $\alpha$, IL-6, IL-1 $\beta$ and vimentin genes caused by thioacetamide. Moreover, it significantly upregulated E-cadherin, glutathione content, and superoxide dismutase. This study showed that AM1241 reduces fibrosis, by activating the CB2 receptor, and inhibiting TLR4/miR-155/NFKB p65 pathway (Ali et al., 2021).

Chronic administration of THC significantly increased the expression of anti-inflammatory miRNAs including miR-187, miR-149, miR-145, miR-99b, miR-24, and miR-10a dysregulated by acute infection with Simian Immunodeficiency Virus (SIV). THC administration also reduced viral load, gastrointestinal inflammation, and the overall disease progression (Chandra et al., 2015). Another study, performed on rhesus macaques with chronic SIV infection with an intention to cause fibrosis, showed that THC prevented fibrosis and upregulated ten

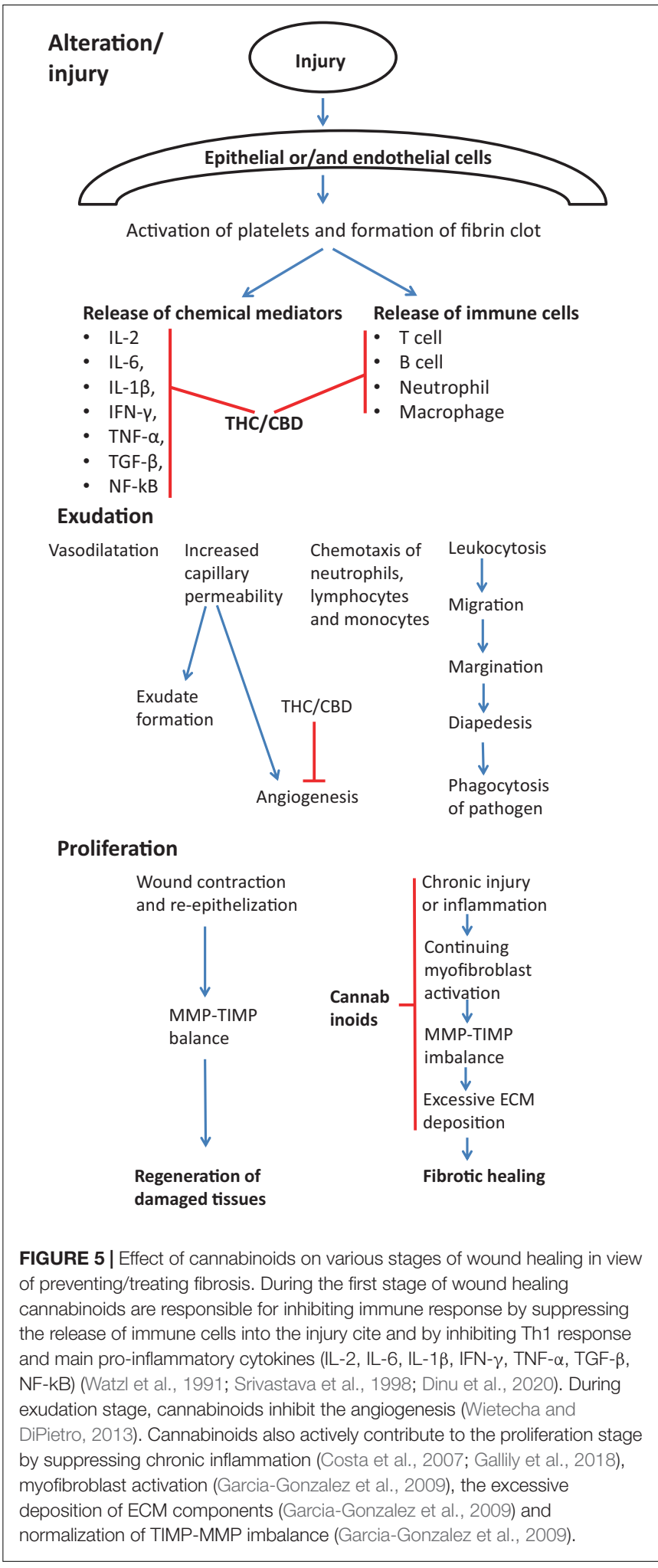

miRNAs, including pro-inflammatory miRNAs miR-21, miR141 and miR-222 and miR-204, that directly targets matrix metalloproteinase 8 (MMP-8), an enzyme that degrades collagen (Kumar et al., 2019). In addition, THC inhibited proliferation 
TABLE 5 | A comparison of target molecules in treatment of fibrosis using modern therapy vs. cannabis treatment.

\begin{tabular}{|c|c|}
\hline A single-component medication: & Cannabis \\
\hline \multicolumn{2}{|c|}{ The mechanism of action of asingle-component medication vs. cannabis } \\
\hline $\begin{array}{l}\text { - TGF- } \beta \text { inhibitor (Pirfenidone) } \\
\text { - PDGFR antagonist (Imatinib) } \\
\text { - TNF inhibitor (Talidomide, Etanercept, Belimumab) } \\
\text { - IL-1 antagonist (Anakinra, Rilonacept) } \\
\text { - IFN- } \gamma \text { stimulant (Actimmune) } \\
\text { - MMP/TIMP inhibitor (Marimastat) } \\
\text { - mTOR inhibitor (Rapamycin) } \\
\text { - JAK-STAT inhibitor (Ruxolitinib) } \\
\text { - PI3K-Akt inhibitor (Omipalisib) } \\
\text { - MAPK inhibitor (MMI-0100) } \\
\text { - NF-kB inhibitor (IMD-1041) } \\
\text { - miR-21 inhibitor (Anti-miR-21) }\end{array}$ & $\begin{array}{l}\text { - TGF- } \beta \text { inhibitor } \\
\text { - TNF inhibitor } \\
\text { - MMP/TIMP inhibitor }\end{array}$ \\
\hline
\end{tabular}

The mechanism of action of a multi-component medication vs. cannabis

A multi-component medication:

Cannabis

- TGF-pc/MMP-2c inhibitor (Fuzhenghuayu)

- TNF- $\alpha /$ TGF- $\beta$ inhibitor (Danggui-Buxue-Tang)

- TGF- $\beta 1 /$ Smad2 inhibitor

and activation of $\mathrm{T}$ cells, suppressed PD-1 expression, and elevated the percentage of anti-inflammatory macrophages in intestinal tissue. These results suggest that THC is an important modulator of miRNA expression and can suppress intestinal inflammation and may prevent lymph node fibrosis (Kumar et al., 2019).

In another study, lipopolysaccharide (LPS) was used to stimulate the BV-2 microglial cells, and CBD had a much more significant effect than THC on the expression of cluster miRNAs (Juknat et al., 2019). While LPS increased the expression of many pro-inflammatory miRNAs, including miR-155, miR-146a, and miR-21, associated with Toll-like receptor (TLR) and NF- $\kappa$ B signaling, the CBD suppressed the expression of miR-155 and miR-146a. Moreover, it was demonstrated that LPS modulates the Notch signaling pathway by increasing the mRNA expression of Notch ligand Dll1. CBD and THC were able to reduce the expression of this ligand. Since the CBD+LPS group increased the expression of miR-34a and downregulated the expression of its target gene Dll1, it was suggested that miR-34a could be involved in the Notch signaling pathway modulation and, as a result, in reducing inflammation (Juknat et al., 2019).

Cannabidiol was demonstrated to trigger apoptosis in human neuroblastoma cell lines by downregulation of let-7a expression and, as a consequence, upregulation of caspase- 3 and several growth arrest genes. In addition, CBD upregulated the expression of has-mir-1972 and caused decreased expression of BCL2L1 and SIRT2 genes (Alharris et al., 2019).

Yet another study showed that THC treatment can suppress the activation of Th1/Th17 lineage commitment via regulation of miRNA expression (Sido et al., 2016). When C57BL/6 mice with delayed-type hypersensitivity were treated with THC, oedema and immune cells infiltration subsided at the place of antigen rechallenge. Delayed-type hypersensitivity caused an increased expression of miR-21 and inhibition of miR-29b; miR-21elevates the Th17 differentiation via inhibiting SMAD7, while miR-29b is
IFN- $\gamma$ inhibitor. THC was able to reverse this miRNA imbalance. Moreover, when primary cells from these mice were transfected with miR-21 inhibitor or miR-29b mimic, the expression of SMAD7 increased, and the expression of IFN- $\gamma$ decreased (Sido et al., 2016).

In another study, when $\mathrm{C} 3 \mathrm{H} / \mathrm{Hej}$ mice were administered staphylococcal enterotoxin B (SEB), it caused an acute mortality; in contrast, mice that received $\mathrm{THC}$ had a $100 \%$ survival rate and did not show any respiratory distress signs, hunched posture, or fur ruffling. In addition, the THC administration significantly reduced the vascular leak in comparison to the staphylococcal enterotoxin B exposure group. The staphylococcal infection caused the induction of miRNA-17-92 cluster, including miR$18 \mathrm{a}$, which targeted the inhibitor of PI3K/Akt pathway, leading to suppression of T regulatory cells (Rao et al., 2015).

Another study showed that THC administered in poststaphylococcal enterotoxin B exposure protected mice from acute respiratory distress syndrome and toxicity. THC significantly downregulated let7a-5p and miR-34-5p, which target SOCS1, FoxP3, NOS1, and CSF1R as well as inhibited the proinflammatory cytokines, such as TNF- $\alpha$ and IFN- $\gamma$. This study suggested that THC can alter miRNA expression in the lungs, suppress the cytokine storm, and as a consequence, might cause mitigation of SEB-mediated pulmonary injury (Mohammed et al., 2020).

A combination of THC plus CBD suppressed neuroinflammation in murine experimental autoimmune encephalomyelitis (EAE) model and suppressed Th1 and Th17 cells via modulating miRNA expression. In addition, this combinational treatment reduced levels of CD4+ T cells and pro-inflammatory molecules such as TNF- $\alpha$, IL- $1 \beta$, IL- 6 , IFN- $\gamma$, IL-17, and TBX21) while elevating anti-inflammatory molecules (IL-4, IL-10, TGF- $\beta$, STAT5b, and FoxP3). Microarray analysis of miRNA of CD4+ T cells showed that THC+CBD administration significantly inhibited miR-122-5p, miR-27b-5p, miR-155-5p, 
miR-150-5p, miR-146a-5p, miR-31-5p, miR-21a-5p and upregulated miR-7116 and miR-706-5p (Al-Ghezi et al., 2019).

miR-29a appears to be one of the regulators of response to cannabinoids. miR-29a diminishes diabetic nephropathy via modulation of CB1 signaling. Upregulated expression of the CB1 receptor, TNF- $\alpha$, IL- 6 , IL- $1 \beta$, collagen IV, and downregulated expression of PPAR- $\gamma$ was noted in streptozotocin-induced diabetic mice. In contrast, overexpression of miR-29a in mice negatively regulated $\mathrm{CB} 1$ receptor, blocking upregulation of pro-inflammatory and fibrogenic compounds, and substantially decreasing kidney hypertrophy. The overexpression of miR-29a also renewed PPAR- $\gamma$ signaling. These data demonstrated that interaction among miR-29a, CB1 receptor, and PPAR- $\gamma$ signaling plays a significant role in protecting renal tissue from developing fibrosis (Tung et al., 2019).

\section{Cannabis and Cannabinoids May Replace the Known Therapies for Fibrosis}

Due to the lack of effective therapies for fibrosis, new more effective and modern therapies with less side effects need to be developed. The currently used drugs suppress the fibrogenetic pathways and reduce the progression of fibrosis. Similarly, cannabis extracts can also affect key profibrotic factors and pathways. Cannabinoid signaling regulates the proliferation and function of fibroblasts which are crucial cells in scar formation. The active suppression of fibroblast proliferation leads to the inhibition of collagen formation and deposition. As previously explained, cannabinoids can actively suppress inflammation by downregulating the pro-inflammatory cytokines such as IL-2, IL-1 $\beta$, TNF- $\alpha$, IFN- $\gamma$, IL-12, IL-8, IL-6, IL-15 (Wang et al., 2020). Due to this effect of cannabis, the fibrosis progression may stop. In comparison with drugs currently applied for treating pulmonary fibrosis, cannabinoids can also suppress the MMP/TIMP, PPAR and other pathways involved in fibrogenesis (Table 5). We can conclude that cannabis affects the same pathways as other drugs currently used medicine in fibrosis treatment, but it has a little- documented negative effects on patients as compared to other drugs used.

\section{CONCLUSION}

Fibrosis is a pathological process that may affect many organs. Significant improvement in understanding the tissue fibrosis

\section{REFERENCES}

Aldair, T., and Montani, J. (2010). "Chapter 1. Overview of Angiogenesis," in Angiogenesis, eds N. Granger and J. Granger (San Rafael: Morgan \& Claypool Life Sciences), 1-10.

Al-Ghezi, Z. Z., Miranda, K., Nagarkatti, M., and Nagarkatti, P. S. (2019). Combination of cannabinoids, $\Delta 9$-tetrahydrocannabinol and cannabidiol, ameliorates experimental multiple sclerosis by suppressing neuroinflammation through regulation of miRNA-mediated signaling pathways. Front. Immunol. 10:1921. doi: 10.3389/fimmu.2019.01921

Alhajj, M., Bansal, P., and Goyal, A. (2020). Physiology, Granulation Tissue. Florida: StatPearls, 4-7. pathways may give us a chance in the future to discover an effective antifibrotic treatment. Many studies have been performed to understand the molecular mechanisms, the cellular basis, and the most prominent characteristics of fibrosis in human organs. Molecules like $\mathrm{TNF} \alpha$ play a key role in the establishment of inflammation and pathogenesis of fibrosis. At the same time, $\mathrm{TNF} \alpha$ may be used a therapeutic agent that can resolve the established pulmonary fibrosis (Redente et al., 2014), further confirming that we do not have a clear picture of mechanisms and pathways of fibrosis.

In most tissues and organs, the fibrosis mechanisms are similar, but the regeneration and regression processes are different across organs and tissues. Mainly this diversity is due to the difference in the regenerative capacity of each tissue or organ (Friedman, 2015).

Based on reports presented in this review, we propose that single cannabinoids and components of cannabis extracts can positively interact with the key profibrotic factors and pathways. In comparison with modern antifibrotic medications, cannabinoids have fewer negative effects on patient's health.

We conclude that modulation of ECS should be a modern approach for the treatment of different fibrotic conditions. This aspect of treatment has not been sufficiently studied. More detailed research should be done to find a patientoriented treatment and improve patients' quality of life. It would be very encouraging to find the curative option for this devastating condition that will help millions of patients worldwide.

\section{AUTHOR CONTRIBUTIONS}

$\mathrm{NP}, \mathrm{OK}$, and IK contributed to the conceptualization and design. NP and MZ contribute to the draft preparation. $\mathrm{OK}$ and IK contributed to the analysis, editing, and supervision. All authors were involved in a review preparation and editing.

\section{ACKNOWLEDGMENTS}

The authors acknowledge the financial support of NSERC and MITACS. The content of the manuscript has been included in NP's Master's thesis.

Alharris, E., Singh, N. P., Nagarkatti, P. S., and Nagarkatti, M. (2019). Role of miRNA in the regulation of cannabidiol-mediated apoptosis in neuroblastoma cells. Oncotarget 10, 45-59. doi: 10.18632/oncotarget. 26534

Ali, A. M., El-Tawil, O. S., Al-Mokaddem, A. K., and Abd El-Rahman, S. S. (2021). Promoted inhibition of TLR4/miR-155/ NFkB p65 signaling by cannabinoid receptor 2 agonist (AM1241), aborts inflammation and progress of hepatic fibrosis induced by thioacetamide. Chem. Biol. Interact. 336, 109398. doi: 10.1016/j.cbi.2021.109398

Allanore, Y., Simms, R., Distler, O., Trojanowska, M., Pope, J., and Denton, C. (2015). Systemic sclerosis. Nat. Rev. Dis. Prim. 1:15002. doi: 10.1038/nrdp. 2015.2 
Apte, M., Pirola, R., and Wilson, J. (2011). The fibrosis of chronic pancreatitis: new insights into the role of pancreatic stellate cells. Antioxid. Redox Signal. 15, 2711-2722. doi: 10.1089/ars.2011.4079

Barratt, S., Creamer, A., Hayton, C., and Chaudhuri, N. (2018). Idiopathic Pulmonary Fibrosis (IPF): an Overview. J. Clin. Med. 7:201. doi: 10.3390/ jcm7080201

Batkai, S., Osei-Hyiaman, D., Pan, H., El-Assal, O., Rajesh, M., and Mukhopadhyay, P. (2007). "Cannabinoid-2 receptor mediates protection against hepatic ischemia/reperfusion injury. FASEB J. 21, 1788-1800. doi: 10.1096/fj.06$7451 \mathrm{com}$

Baum, J., and Duffy, H. S. (2011). CityPaws Animal Hospital 1823. J. Cardiovasc. Pharmacol. 57, 376-379. doi: 10.1097/FJC.0b013e3182116e39

Bochaton-Piallat, M. L., Gabbiani, G., and Hinz, B. (2016). The myofibroblast in wound healing and fibrosis: answered and unanswered questions. F1000Res. 5:F1000 . doi: 10.12688/f1000research.8190.1

Burstein, S. (2021). Molecular Mechanisms for the Inflammation-Resolving Actions of Lenabasum. Mol. Pharmacol. 99, 125-132. doi: 10.1124/molpharm. 120.000083

Cañedo-Dorantes, L., and Cañedo-Ayala, M. (2019). Skin acute wound healing: a comprehensive review. Int. J. Inflam. 2019:15. doi: 10.1155/2019/37 06315

Chandra, L. C., Kumar, V., and Torben, W. (2015). Chronic Administration of $\Delta 9$-Tetrahydrocannabinol Induces Intestinal Anti-Inflammatory MicroRNA Expression during Acute Simian Immunodeficiency Virus Infection of Rhesus Macaques. J. Virol. 89, 1168-1181. doi: 10.1128/JVI.01754-14

Chau, B. N., Xin, C., Hartner, J., Ren, S., Castano, A. P., Linn, G., et al. (2012). MicroRNA 21 promotes fibrosis of the kidney by silencing metabolic pathways. Sci. Transl. Med. 4, 121-139. doi: 10.1126/scitranslmed.3003205

Chiurchiù, V. (2016). Endocannabinoids and Immunity. Cannabis Cannabinoid Res. 1, 59-66. doi: 10.1089/can.2016.0002

Costa, B., Trovato, A. E., Comelli, F., Giagnoni, G., and Colleoni, M. (2007). The non-psychoactive cannabis constituent cannabidiol is an orally effective therapeutic agent in rat chronic inflammatory and neuropathic pain. Eur. J. Pharmacol. 556, 75-83. doi: 10.1016/j.ejphar.2006.11.006

de Meijer, V. E., Sverdlov, D. Y., Popov, Y., Le, H. D., Meisel, J. A., and Nose, V. (2010). Broad-spectrum matrix metalloproteinase inhibition curbs inflammation and liver injury but aggravates experimental liver fibrosis in mice. PLoS One 5:e11256. doi: 10.1371/journal.pone.0011256

de Oliveira, R. C., and Wilson, S. E. (2020). Fibrocytes, wound healing, and corneal fibrosis. Invest. Ophthalmol. Vis. Sci. 61:28. doi: 10.1167/iovs.61.2.28

Dinu, A. R., Florin Rogobete, A., Bratu, T., Popovici, S. E., Bedreag, O. H., and Papurica, M. (2020). "Cannabis Sativa Revisited-Crosstalk between microRNA Expression, Inflammation, Oxidative Stress, and Endocannabinoid Response System in Critically Ill Patients with Sepsis. Cells 9, 1-23. doi: 10.3390/ cells 9020307

Elli, E. M., Baratè, C., Mendicino, F., Palandri, F., and Palumbo, G. A. (2019). Mechanisms Underlying the Anti-inflammatory and Immunosuppressive Activity of Ruxolitinib. Front. Oncol. 9:1186. doi: 10.3389/fonc.2019.01186

Farghaly, S., and El-Abdin, A. Z. (2015). Pulmonary fibrosis as a risk factor for thromboembolic disease. Egypt. J. Bronchol. 9, 160-164. doi: 10.4103/16878426.158056

Frangogiannis, N. G. (2020). Transforming growth factor- $\beta$ in tissue fibrosis. J. Exp. Med. 217:e20190103. doi: 10.1084/jem.20190103

Friedlander, M. (2007). Fibrosis and diseases of the eye. J. Clin. Invest. 117, 576-586. doi: $10.1172 /$ JCI31030

Friedman, S. L. (2015). Clarity and Challenges in Tissue Fibrosis. in Innovative Medicine. Japan: Springer, 187-194. doi: 10.1007/978-4-431-55651-0_16

Fu, Q., Zheng, Y., Dong, X., Wang, L., and Jiang, C. G. (2017). Activation of cannabinoid receptor type 2 by JWH133 alleviates bleomycin-induced pulmonary fibrosis in mice. Oncotarget 8, 103486-103498. doi: 10.18632/ oncotarget.21975

Fu, R., Wu, J., Ding, J., Sheng, J., Hong, L., and Sun, Q. (2011). “Targeting transforming growth factor $\beta$ RII expression inhibits the activation of hepatic stellate cells and reduces collagen synthesis. Exp. Biol. Med. 236, 291-297. doi: 10.1258/ebm.2010.010231

Fujimoto, H., Kobayashi, T., and Azuma, A. (2015). Idiopathic Pulmonary Fibrosis Treatment - OFEV\$(nintedanib) Capsules. Clin. Med. Insights Circ. Respir. Pulm. Med. 9, 179-185. doi: 10.4137/CCRPM.S23321
Gallily, R., Yekhtin, Z., and Hanuš, L. O. (2018). The Anti-Inflammatory Properties of Terpenoids from Cannabis. Cannabis Cannabinoid Res. 3, 282-290. doi: 10.1089/can.2018.0014

Galliot, B., Crescenzi, M., Jacinto, A., and Tajbakhsh, S. (2017). Trends in tissue repair and regeneration. Development 144, 357-364. doi: 10.1242/dev.144279

Garcia-Gonzalez, E., Selvi, E., Balistreri, E., Lorenzini, S., and Maggio, R. (2009). Maria-Rita Natale "Cannabinoids inhibit fibrogenesis in diffuse systemic sclerosis fibroblasts. Rheumatology 48, 1050-1056. doi: 10.1093/rheumatology/ kep189

Gauglitz, G. G., Korting, H. C., Pavicic, T., Ruzicka, T., and Jeschke, M. G. (2011). Hypertrophic scarring and keloids: pathomechanisms and current and emerging treatment strategies. Mol. Med. 17, 113-125. doi: 10.2119/molmed. 2009.00153

Ghahary, A., Tredget, E. E., Shen, Q., Kilani, R. T., Scott, P. G., and Houle, Y. (2000). Mannose-6-phosphate/IGF-II receptors mediate the effects of IGF-1induced latent transforming growth factor $\beta 1$ on expression of type I collagen and collagenase in dermal fibroblasts. Growth Factors 17, 167-176. doi: 10. 3109/08977190009001066

Giannone, F. A., Baldassarre, M., Domenicali, M., Zaccherini, G., Trevisani, F., and Bernardi, M. (2012). Reversal of liver fibrosis by the antagonism of endocannabinoid CB1 receptor in a rat model of $\mathrm{CCl} 4$-induced advanced cirrhosis. Lab. Invest. 92, 384-395. doi: 10.1038/labinvest.2011.191

Gonzalez, A. C. D. O., Andrade, Z. D. A., Costa, T. F., and Medrado, A. R. A. P. (2016). Wound healing - A literature review. An. Bras. Dermatol. 91, 614-620. doi: 10.1590/abd1806-4841.20164741

Gonzalez, E. G., Selvi, E., Balistreri, E., Akhmetshina, A., Palumbo, K., and Lorenzini, S. (2012). Synthetic cannabinoid ajulemic acid exerts potent antifibrotic effects in experimental models of systemic sclerosis. Ann. Rheum. Dis. 71, 1545-1551. doi: 10.1136/annrheumdis-2011-200314

Harmanci, D., Erkan, E. P., Kocak, A., and Akdogan, G. G. (2017). Role of the microRNA-29 family in fibrotic skin diseases. Biomed. Rep. 6, 599-604. doi: 10.3892/br.2017.900

Hinden, L., Udi, S., Drori, A., Gammal, A., Nemirovski, A., and Hadar, R. (2018). Modulation of Renal GLUT2 by the Cannabinoid-1 Receptor: implications for the Treatment of Diabetic Nephropathy. J. Am. Soc. Nephrol. 29, 434-448. doi: 10.1681/ASN.2017040371

Hinderer, S., and Schenke-Layland, K. (2019). Cardiac fibrosis - A short review of causes and therapeutic strategies. Adv. Drug Deliv. Rev. 146, 77-82. doi: 10.1016/j.addr.2019.05.011

Ho, C. Y., López, B., Coelho-Filho, O. R., Lakdawala, N. K., Cirino, A. L., and Jarolim, M. S. P. (2010). Myocardial Fibrosis as an Early Manifestation of Hypertrophic Cardiomyopathy. N. Engl. J. Med. 363, 552-563. doi: 10.1056/ NEJMoa1002659

Hosein Mohimani, P. A. P., Gurevich, A., Mikheenko, A., Garg, N., Nothias, L.-F., Ninomiya, A., et al. (2017). HHS Public Access. Physiol. Behav. 176, 139-148.

Hoyer, N., Prior, T. S., Bendstrup, E., Wilcke, T., and Shaker, S. B. (2019). Risk factors for diagnostic delay in idiopathic pulmonary fibrosis. Respir. Res. 20:103. doi: 10.1186/s12931-019-1076-0

Huang, S. K., White, E. S., Wettlaufer, S. H., Grifka, H., Hogaboam, C. M., and Thannickal, V. J. (2009). Prostaglandin E2 induces fibroblast apoptosis by modulating multiple survival pathways. FASEB J. 23:4317. doi: 10.1096/fj.08128801

Hughes, G., Toellner, H., Morris, H., Leonard, C., and Chaudhuri, N. (2016). Real World Experiences: pirfenidone and Nintedanib are Effective and Well Tolerated Treatments for Idiopathic Pulmonary Fibrosis. J. Clin. Med. 5:78. doi: $10.3390 / \mathrm{jcm} 5090078$

Iannitti, R. G., Napolioni, V., Oikonomou, V., De Luca, A., Galosi, C., and Pariano, M. (2016). ARTICLE IL-1 receptor antagonist ameliorates inflammasomedependent inflammation in murine and human cystic fibrosis. Nat. Commun. 7:10791. doi: 10.1038/ncomms10791

Jeon, K. I., Phipps, R. P., Sime, P. J., and Huxlin, K. R. (2017). Antifibrotic Actions of Peroxisome Proliferator-Activated Receptor $\gamma$ Ligands in Corneal Fibroblasts Are Mediated by $\beta$-Catenin-Regulated Pathways. Am. J. Pathol. 187, 1660-1669. doi: 10.1016/j.ajpath.2017.04.002

Juknat, A., Gao, F., Coppola, G., Vogel, Z., and Kozela, E. (2019). miRNA expression profiles and molecular networks in resting and LPS-activated BV2 microglia-Effect of cannabinoids. PLoS One 14:e0212039. doi: 10.1371/ journal.pone.0212039 
Kelly, P., Meade, K. G., and O'Farrelly, C. (2019). Non-canonical inflammasomemediated IL-1 $\beta$ production by primary endometrial epithelial and stromal fibroblast cells is NLRP3 and caspase-4 dependent. Front. Immunol. 10:102. doi: 10.3389/fimmu.2019.00102

Kendall, R. T., and Feghali-Bostwick, C. A. (2014). Fibroblasts in fibrosis: novel roles and mediators. Front. Pharmacol. 5:123. doi: 10.3389/fphar.2014.00123

Khaksar, S., and Bigdeli, M. R. (2017). Anti-excitotoxic effects of cannabidiol are partly mediated by enhancement of NCX2 and NCX3 expression in animal model of cerebral ischemia. Eur. J. Pharmacol. 794, 270-279. doi: 10.1016/j. ejphar.2016.11.011

Khan, R., and Sheppard, R. (2006). Fibrosis in heart disease: understanding the role of transforming growth factor- $\beta 1$ in cardiomyopathy, valvular disease and arrhythmia. Immunology 118, 10-24. doi: 10.1111/j.1365-2567.2006.02336.x

Khaw, P. T., Bouremel, Y., Brocchini, S., and Henein, C. (2020). The control of conjunctival fibrosis as a paradigm for the prevention of ocular fibrosisrelated blindness. 'Fibrosis has many friends,"'. Eye 34, 2163-2174. doi: 10.1038/ s41433-020-1031-9

Kim, I. H., Kisseleva, T., and Brenner, D. A. (2015). Aging and liver disease. Curr. Opin. Gastroenterol. 31, 184-191. doi: 10.1097/MOG.0000000000000176

Klinkhammer, B. M., Floege, J., and Boor, P. (2018). PDGF in organ fibrosis. Mol. Aspects Med. 62, 44-62. doi: 10.1016/j.mam.2017.11.008

Klöppel, G. (2007). Chronic pancreatitis, pseudotumors and other tumor-like lesions. Mod. Pathol. 20, 113-131. doi: 10.1038/modpathol.3800690

Klöppel, G., Detlefsen, S., and Feyerabend, B. (2004). Fibrosis of the pancreas: the initial tissue damage and the resulting pattern. Virchows Arch. 445, 1-8. doi: 10.1007/s00428-003-0958-0

Kobayashi, T., Tanaka, K., Fujita, T., Umezawa, H., Amano, H., and Yoshioka, K. (2015). Bidirectional role of IL-6 signal in pathogenesis of lung fibrosis. Respir. Res. 16, 1-14. doi: 10.1186/s12931-015-0261-z

Kotsiou, O. S., Gourgoulianis, K. I., and Zarogiannis, S. G. (2018). IL-33/ST2 axis in organ fibrosis. Front. Immunol. 9:2432. doi: 10.3389/fimmu.2018.02432

Kovalchuk, O., and Kovalchuk, I. (2020). Cannabinoids as anticancer therapeutic agents. Cell Cycle 19, 961-989. doi: 10.1080/15384101.2020.1742952

Kowal-Bielecka, O., Kowal, K., Distler, O., and Gay, S. (2007). Mechanisms of Disease: leukotrienes and lipoxins in scleroderma lung disease-insights and potential therapeutic implications. Nat. Clin. Pract. Rheumatol. 3, 43-51. doi: 10.1038/ncprheum0375

Kryczka, J., and Boncela, J. (2015). Leukocytes: the Double-Edged Sword in Fibrosis. Mediators Inflamm. 2015, 1-10. doi: 10.1155/2015/652035

Kumar, V., Torben, W., Mansfield, J., Alvarez, X., Vande Stouwe, C., and Li, J. (2019). Cannabinoid Attenuation of Intestinal Inflammation in Chronic SIV-Infected Rhesus Macaques Involves T Cell Modulation and Differential Expression of Micro-RNAs and Pro-inflammatory Genes. Front. Immunol. 10:914. doi: 10.3389/fimmu.2019.00914

Laezza, C., Pagano, C., Navarra, G., Pastorino, O., Chiara Proto, M., and Fiore, D. (2020). The endocannabinoid system: a target for cancer treatment. Int. J. Mol. Sci. 21:747. doi: 10.3390/ijms21030747

Lafaye, G., Karila, L., Blecha, L., and Benyamina, A. (2017). Cannabis, cannabinoids, and health. Dialogues Clin. Neurosci. 19, 309-316. doi: 10.31887/ DCNS.2017.19.3/glafaye

Lands, L. C., and Stanojevic, S. (2019). Oral non-steroidal anti-inflammatory drug therapy for lung disease in cystic fibrosis. Cochrane Database Syst. Rev. 4:CD001505. doi: 10.1002/14651858.CD001505.pub5

Ley, B., and Collard, H. R. (2013). Epidemiology of idiopathic pulmonary fibrosis. Clin. Epidemiol. 5, 483-492. doi: 10.2147/CLEP.S54815

Li, D., Guabiraba, R., Besnard, A., Komai-Koma, M., Jabir, M. S., and Zhang, L. (2014). IL-33 promotes ST2-dependent lung fibrosis by the induction of alternatively activated macrophages and innate lymphoid cells in mice. J. Allergy Clin. Immunol. 134, 1422-1432.e11. doi: 10.1016/j.jaci.2014.05.011

Li, X., Hana, D., Tianc, Z., Gaoa, B., Fana, M., and Lia, C. (2016). Activation of Cannabinoid Receptor Type II by AM1241 Ameliorates Myocardial Fibrosis via Nrf2-Mediated Inhibition of TGF- $\beta 1 /$ Smad3 Pathway in Myocardial Infarction Mice. Cell. Physiol. Biochem. 39, 1521-1536. doi: 10.1159/000447855

Li, X., Zhu, L., Wang, B., Yuan, M., and Zhu, R. (2017). Drugs and targets in fibrosis. Front. Pharmacol. 8:855. doi: 10.3389/fphar.2017.00855

Lim, M. P., Devi, L. A., and Rozenfeld, R. (2011). Cannabidiol causes activated hepatic stellate cell death through a mechanism of endoplasmic reticulum stress-induced apoptosis. Cell Death Dis. 2:e170. doi: 10.1038/cddis.2011.52
Liu, G., Friggeri, A., Yang, Y., Milosevic, J., Ding, Q., and Thannickal, V. J. (2010). miR-21 mediates fibrogenic activation of pulmonary fibroblasts and lung fibrosis. J. Exp. Med. 207, 1589-1597. doi: 10.1084/jem.20100035

Liu, Y. (2011). Cellular and molecular mechanisms of renal fibrosis. Nat. Rev. Nephrol. 7, 684-696. doi: 10.1038/nrneph.2011.149

Liu, Z., Changa, A. N., Grinnellb, F., Trybusc, K. M., Milewiczd, D. M., and Stull, J. T. (2017). Vascular disease-causing mutation, smooth muscle $\alpha$-actin R258C, dominantly suppresses functions of $\alpha$-actin in human patient fibroblasts. Proc. Natl. Acad. Sci. U. S. A. 114, E5569-E5578. doi: 10.1073/pnas.1703506114

Lopez-Castejon, G., and Brough, D. (2011). Understanding the mechanism of IL$1 \beta$ secretion. Cytokine Growth Factor Rev. 22, 189-195. doi: 10.1016/j.cytogfr. 2011.10.001

Lv, J., Zhao, Z., Chen, Y., Wang, Q., Tao, Y., and Yang, L. (2012). The Chinese herbal decoction Danggui Buxue Tang inhibits angiogenesis in a rat model of liver fibrosis. Evid. Based Complement Alternat. Med. 2012:284963. doi: $10.1155 / 2012 / 284963$

Macara, I. G., Guyer, R., Richardson, G., Huo, Y., and Ahmed, S. M. (2014). Epithelial homeostasis. Curr. Biol. 24, R815-R825. doi: 10.1016/j.cub.2014.06. 068

Madácsy, T., Pallagi, P., and Maleth, J. (2018). Cystic Fibrosis of the Pancreas: the Role of CFTR Channel in the Regulation of Intracellular Ca2+ Signaling and Mitochondrial Function in the Exocrine Pancreas. Front. Physiol. 9:1585. doi: 10.3389/fphys.2018.01585

Mahesh, G., and Biswas, R. (2019). MicroRNA-155: A Master Regulator of Inflammation. Journal of Interferon and Cytokine Research. Available online at: https://pubmed.ncbi.nlm.nih.gov/30998423/. ([Accessed: April 11, -Apr2021)]. doi: $10.1089 /$ jir.2018.0155

Mallat, A., Teixeira-Clerc, F., Deveaux, V., Manin, S., and Lotersztajn, S. (2011). The endocannabinoid system as a key mediator during liver diseases: new insights and therapeutic openings. Br. J. Pharmacol. 163, 1432-1440. doi: 10.1111/j.1476-5381.2011.01397.x

Margaritopoulos, G. A., Vasarmidi, E., and Antoniou, K. M. (2016). Pirfenidone in the treatment of idiopathic pulmonary fibrosis: an evidence-based review of its place in therapy. Core Evid. 11, 11-22. doi: 10.2147/CE.S7 6549

Marone, G., Granata, F., Pucino, V., Pecoraro, A., Heffler, E., and Loffredo, S. (2019). The intriguing role of interleukin 13 in the pathophysiology of asthma. Front. Pharmacol. 10:1387. doi: 10.3389/fphar.2019. 01387

Maurer, B., Stanczyk, J., Jungel, A., Akhmetshina, A., Trenkmann, M., and Brock, M. (2010). MicroRNA-29, a key regulator of collagen expression in systemic sclerosis. Arthritis Rheum. 62, 1733-1743. doi: 10.1002/art.27443

McVicker, B. L., and Bennett, R. G. (2017). Novel anti-fibrotic therapies. Front. Pharmacol. 8:318. doi: 10.3389/fphar.2017.00318

Meng, X. M., Tang, P. M. K., Li, J., and Lan, H. Y. (2015). TGF-ß/Smad signaling in renal fibrosis. Front. Physiol. 6:82. doi: 10.3389/fphys.2015.00082

Mohammed, A., Alghetaa, H., Sultan, M., Singh, N. P., Nagarkatti, P., and Nagarkatti, M. (2020). Administration of $\Delta$ 9-Tetrahydrocannabinol (THC) Post-Staphylococcal Enterotoxin B Exposure Protects Mice From Acute Respiratory Distress Syndrome and Toxicity. Front. Pharmacol. 11:893. doi: 10.3389/fphar.2020.00893

Montecucco, F., and Di Marzo, V. (2012). At the heart of the matter: the endocannabinoid system in cardiovascular function and dysfunction. Trends Pharmacol. Sci. 33, 331-340. doi: 10.1016/j.tips.2012.03.002

Moran-Mendoza, O., Colman, R., Kalluri, M., Cabalteja, C., and Harle, I. (2019). A comprehensive and practical approach to the management of idiopathic pulmonary fibrosis. Expert Rev. Respir. Med. 13, 601-614. doi: 10.1080/ 17476348.2019.1627204

Moshref, S. S., Mufti, S. T., Moshref, S. S., and Mufti, S. T. (2010). Keloid and Hypertrophic Scars: comparative Histopathological and Immunohistochemical Study. JKAU Med. Sci 17, 3-22. doi: 10.4197/Med.17-3.1

Muñoz-Luque, J., Ros, J., Fernández-Varo, G., Tugues, S., Morales-Ruiz, M., and Alvarez, C. E. (2008). "Regression of fibrosis after chronic stimulation of cannabinoid CB2 receptor in cirrhotic rats. J. Pharmacol. Exp. Ther. 324, 475-483. doi: 10.1124/jpet.107.131896

Nagarkatti, P., Pandey, R., Rieder, S. A., Hegde, V. L., and Nagarkatti, M. (2009). Cannabinoids as novel anti-inflammatory drugs. Future Med. Chem. 1, 13331349. doi: $10.4155 /$ fmc. 09.93 
Newton, K., and Dixit, V. M. (2012). Signaling in innate immunity and inflammation. Cold Spring Harb. Perspect. Biol. 4:a006049. doi: 10.1101/ cshperspect.a006049

Occleston, N. L., Metcalfe, A. D., Boanas, A., Burgoyne, N. J., Nield, K., and O’Kane, S. (2010). Therapeutic improvement of scarring: mechanisms of scarless and scar-forming healing and approaches to the discovery of new treatments. Dermatol. Res. Pract. 2010:405262. doi: 10.1155/2010/405262

Panganiban, R. A. M., and Day, R. M. (2011). Hepatocyte growth factor in lung repair and pulmonary fibrosis. Acta Pharmacol. Sin. 32, 12-20. doi: 10.1038/ aps. 2010.90

Panizo, S., Martínez-Arias, L., Alonso-Montes, C., Cannata, P., Martín-Carro, B., and Fernández-Martín, J. L. (2021). Fibrosis in chronic kidney disease: pathogenesis and consequences. Int. J. Mol. Sci. 22, 1-19. doi: 10.3390/ ijms 22010408

Papetti, M., and Herman, I. M. (2002). Mechanisms of normal and tumor-derived angiogenesis. Am. J. Physiol. Cell Physiol. 282, C947-70. doi: 10.1152/ajpcell. 00389.2001

Parfieniuk, A., and Flisiak, R. (2008). Role of cannabinoids in chronic liver diseases. World J. Gastroenterol. 14, 6109-6114. doi: 10.3748/wjg.14.6109

Patsenker, E., and Stickel, F. (2016). Cannabinoids in liver diseases. Clin. Liver Dis. 7, 21-25. doi: 10.1002/cld.527

Pilewski, J. M., Liu, L., Henry, A. C., Knauer, A. V., and Feghali-Bostwick, C. A. (2005). Insulin-like growth factor binding proteins 3 and 5 are overexpressed in idiopathic pulmonary fibrosis and contribute to extracellular matrix deposition. Am. J. Pathol. 166, 399-407. doi: 10.1016/S0002-9440(10)62263-8

Profyris, C., Tziotzios, C., and Do Vale, I. (2012). Cutaneous scarring: pathophysiology, molecular mechanisms, and scar reduction therapeutics: part I. the molecular basis of scar formation. J. Am. Acad. Dermatol. 66, 1-10. doi: 10.1016/j.jaad.2011.05.055

Rabello, F. B., Souza, C. D., and Farina, J. A. (2014). Update on hypertrophic scar treatment. Clinics 69, 565-573. doi: 10.6061/clinics/2014(08)11

Raimundo, K., Chang, E., Broder, M. S., Alexander, K., Zazzali, J., and Swigris, J. J. (2016). Clinical and economic burden of idiopathic pulmonary fibrosis: a retrospective cohort study. BMC Pulm. Med. 16:2. doi: 10.1186/s12890-0150165-1

Rajput, A., Rajan, K., Vardhan, V., Tewari, S., and Borcar, J. (2000). Mediastinal Fibrosis. Med. J. Armed Forces India 56, 82-84. doi: 10.1016/S0377-1237(17) 30106-5

Rao, R., Nagarkatti, P. S., and Nagarkatti, M. (2015). $\Delta 9$ Tetrahydrocannabinol attenuates Staphylococcal enterotoxin B-induced inflammatory lung injury and prevents mortality in mice by modulation of miR-17-92 cluster and induction of T-regulatory cells. Br. J. Pharmacol. 172, 1792-1806. doi: 10.1111/bph. 13026

Redente, E. F., Keith, R. C., Janssen, W., Henson, P. M., Ortiz, L. A., and Downey, G. P. (2014). "Tumor necrosis factor- $\alpha$ accelerates the resolution of established pulmonary fibrosis in mice by targeting profibrotic lung macrophages. Am. J. Respir. Cell Mol. Biol. 50, 825-837. doi: 10.1165/rcmb.2013-0386OC

Reinke, J. M., and Sorg, H. (2012). Wound repair and regeneration. Eur. Surg. Res. 49, 35-43. doi: 10.1159/000339613

Rizzo, M. D., Crawford, R. B., Henriquez, J. E., Aldhamen, Y. A., Gulick, P., and Amalfitano, A. (2018). HIV-infected cannabis users have lower circulating CD16+ monocytes and IFN- $\gamma$-inducible protein 10 levels compared with nonusing HIV patients. AIDS 32, 419-429. doi: 10.1097/QAD. 0000000000001704

Robertson, S., and Miller, M. R. (2018). Ambient air pollution and thrombosis. Part. Fibre Toxicol. 15, 1-16. doi: 10.1186/s12989-017-0237-x

Rosales, C. (2018). Neutrophil: a cell with many roles in inflammation or several cell types? Front. Physiol. 9:113. doi: 10.3389/fphys.2018.00113

Rosenkranz, S. (2004). TGF- $\beta 1$ and angiotensin networking in cardiac remodeling. Cardiovasc. Res. 63, 423-432. doi: 10.1016/j.cardiores.2004.04.030

Russo, E. B. (2019). The case for the entourage effect and conventional breeding of clinical cannabis: no 'Strain,' no gain. Front. Plant Sci. 9:1969. doi: 10.3389/fpls. 2018.01969

Sakai, N., and Tager, A. M. (2013). Fibrosis of two: epithelial cell-fibroblast interactions in pulmonary fibrosis. Biochim. Biophys. Acta 1832, 911-21. doi: 10.1016/j.bbadis.2013.03.001

Sanders, D. B., and Fink, A. K. (2016). Background and Epidemiology. Pediatr. Clin. North Am. 63, 567-584. doi: 10.1016/j.pcl.2016.04.001
Sepanlou, S. G. (2020). The global, regional, and national burden of cirrhosis by cause in 195 countries and territories, 1990-2017: a systematic analysis for the Global Burden of Disease Study 2017. Lancet Gastroenterol. Hepatol. 5, 245-266. doi: 10.1016/S2468-1253(19)30349-8

Servettaz, A., Kavian, N., Nicco, C., Deveaux, V., Chereau, C., and Wang, A. (2010). "Targeting the cannabinoid pathway limits the development of fibrosis and autoimmunity in a mouse model of systemic sclerosis. Am. J. Pathol. 177, 187-196. doi: 10.2353/ajpath.2010.090763

Sido, J. M., Jackson, A. R., Nagarkatti, P. S., and Nagarkatti, M. (2016). Marijuanaderived $\Delta$-9-tetrahydrocannabinol suppresses Th1/Th17 cell-mediated delayed-type hypersensitivity through microRNA regulation. J. Mol. Med. 94, 1039-1051. doi: 10.1007/s00109-016-1404-5

Simon, T. G., Henson, J., Osganian, S., Masia, R., Chan, A. T., and Chung, R. T. (2019). Daily Aspirin Use Associated With Reduced Risk For Fibrosis Progression In Patients With Nonalcoholic Fatty Liver Disease. Clin. Gastroenterol. Hepatol. 17, 2776-2784.e4. doi: 10.1016/j.cgh.2019.04.061

Šmíd, V. (2020). Liver fibrosis. Vnitr. Lek. 66, e36-e41. doi: 10.36290/vnl.2020.078 Smith, J. S., Gorbett, D., Mueller, J., Perez, R., and Daniels, C. J. (2013). Pulmonary hypertension and idiopathic pulmonary fibrosis: a dastardly duo. Am. J. Med. Sci. 346, 221-225. doi: 10.1097/MAJ.0b013e31827871dc

Spiera, R., Kuwana, M., Khanna, D., Hummers, L., Frech, T., and Stevens, W. (2021). OP0171 Phase 3 trial of Lenabasum, a CB2 agonist, for the treatment of diffuse cutaneous systemic sclerosis (DCSSC). Ann. Rheum. Dis. 80, 102-103. doi: 10.1136/annrheumdis-2021-eular.1795

Srivastava, M. D., Srivastava, B. I. S., and Brouhard, B. (1998). $\Delta 9$ Tetrahydrocannabinol and cannabidiol alter cytokine production by human immune cells. Immunopharmacology 40, 179-185. doi: 10.1016/S0162-3109(98)00041-1

Sun, S., Hu, F., Wu, J., and Zhang, S. (2017). Cannabidiol attenuates OGD/Rinduced damage by enhancing mitochondrial bioenergetics and modulating glucose metabolism via pentose-phosphate pathway in hippocampal neurons. Redox Biol. 11, 577-585. doi: 10.1016/j.redox.2016.12.029

Suthahar, N., Meijers, W. C., Silljé, H. H. W., and de Boer, R. A. (2017). From Inflammation to Fibrosis-Molecular and Cellular Mechanisms of Myocardial Tissue Remodelling and Perspectives on Differential Treatment Opportunities. Curr. Heart Fail. Rep. 14, 235-250. doi: 10.1007/s11897-017-0343-y

Tam, J., Liu, J., Mukhopadhyay, B., Cinar, R., Godlewski, G., and Kunos, G. (2011). Endocannabinoids in liver disease. Hepatology 53, 346-355. doi: 10.1002/hep. 24077

Tanaka, T., Narazaki, M., and Kishimoto, T. (2014). Il-6 in inflammation, Immunity, And disease. Cold Spring Harb. Perspect. Biol. 6, 16295-16296. doi: 10.1101/cshperspect.a016295

Tanaka, T., Ogawa, M., Suzuki, J., Sekinishi, A., Itai, A., and Hirata, Y. (2012). Inhibition of IкB phosphorylation prevents load-induced cardiac dysfunction in mice. Am. J. Physiol. Circ. Physiol. 303, H1435-H1445. doi: 10.1152/ajpheart. 00290.2012

Thum, T., Gross, C., Fiedler, J., Fischer, T., Kissler, S., and Bussen, M. (2008). MicroRNA-21 contributes to myocardial disease by stimulating MAP kinase signalling in fibroblasts. Nature 456, 980-984. doi: 10.1038/nature07511

Tirado, M., and Koss, W. (2018). Differentiation of mesothelial cells into macrophage phagocytic cells in a patient with clinical sepsis. Blood 132:1460. doi: 10.1182/blood-2018-07-859991

Tung, C. W., Ho, C., Hsu, Y. C., Huang, S. C., Shih, Y. H., and Lin, C. L. (2019). MicroRNA-29a attenuates diabetic glomerular injury through modulating cannabinoid receptor 1 signaling. Molecules 24:264. doi: 10.3390/ molecules24020264

Turcotte, C., Blanchet, M. R., Laviolette, M., and Flamand, N. (2016). The CB2 receptor and its role as a regulator of inflammation. Cell Mol. Life Sci. 73, 4449-4470. doi: 10.1007/s00018-016-2300-4

Usher, K. M., Zhu, S., Mavropalias, G., Carrino, J. A., Zhao, J., and Xu, J. (2019). Pathological mechanisms and therapeutic outlooks for arthrofibrosis. Bone Res. 7, 9. doi: 10.1038/s41413-019-0047-x

Vaglio, A., and Maritati, F. (2016). Idiopathic retroperitoneal fibrosis. J. Am. Soc. Nephrol. 27, 1880-1889. doi: 10.1681/ASN.2015101110

Valenzuela, C., Torrisi, S. E., Kahn, N., Quaresma, M., Stowasser, S., and Kreuter, M. (2020). Ongoing challenges in pulmonary fibrosis and insights from the nintedanib clinical programme. Respir. Res. 21, 1-15. doi: 10.1186/s12931-0191269-6 
Vallée, A., Lecarpentier, Y., Guillevin, R., and Vallée, J. N. (2017). Interactions between TGF-\&\#x03B2;1, canonical WNT/\&\#x03B2;-catenin pathway and PPAR \&\#x03B3; in radiation-induced fibrosis. Oncotarget 8, 90579-90604. doi: 10.18632/oncotarget. 21234

Waikhom, R., and Taraphder, A. (2011). Nephrogenic systemic fibrosis: a brief review. Indian J. Dermatol. 56, 54. doi: 10.4103/0019-5154.77554

Walker, O. L. S., Gurm, H., Sharma, R., Verma, N., May, L. L., and Raha, S. (2021). Delta-9-tetrahydrocannabinol inhibits invasion of HTR8/SVneo human extravillous trophoblast cells and negatively impacts mitochondrial function. Sci. Rep. 11:4029. doi: 10.1038/s41598-021-83563-9

Wang, B., Kovalchuk, A., Li, D., Rodriguez-Juarez, R., Ilnytskyy, Y., Kovalchuk, I., et al. (2020). In search of preventive strategies: novel high-CBD Cannabis sativa extracts modulate ACE2 expression in COVID-19 gateway tissues. Aging 12, 22425-22440. doi: 10.20944/preprints202004.0315.v1

Watzl, B., Scuderi, P., and Watson, R. R. (1991). Marijuana components stimulate human peripheral blood mononuclear cell secretion of interferon-gamma and suppress interleukin-1 alpha in vitro. Int. J. Immunopharmacol. 13, 1091-1097. doi: 10.1016/0192-0561(91)90160-9

Weiskirchen, R., Weiskirchen, S., and Tacke, F. (2019). Organ and tissue fibrosis: molecular signals, cellular mechanisms and translational implications. Mol. Aspects Med. 65, 2-15. doi: 10.1016/j.mam.2018.06.003

Wernig, G., Chenc, S., Cuib, L., Van Nesteb, C., Tsaia, J. M., and Kambham, N. (2017). Unifying mechanism for different fibrotic diseases. Proc. Natl. Acad. Sci. U. S. A. 114, 4757-4762. doi: 10.1073/pnas.1621375114

Wietecha, M. S., and DiPietro, L. A. (2013). Therapeutic Approaches to the Regulation of Wound Angiogenesis. Adv. Wound Care 2, 81-86. doi: 10.1089/ wound. 2011.0348

Wind, S., Schmid, U., Freiwald, M., Marzin, K., Lotz, R., and Ebner, T. (2019). Clinical Pharmacokinetics and Pharmacodynamics of Nintedanib. Clin. Pharmacokinet. 58, 1131-1147. doi: 10.1007/s40262-019-00766-0

Wolff, V., Schlagowski, A. I., Rouyer, O., Charles, A. L., Singh, F., Auger, C., et al. (2015). Tetrahydrocannabinol induces brain mitochondrial respiratory Chain dysfunction and increases oxidative stress: a potential mechanism involved in cannabis-related stroke. Biomed Res. Int. 2015:323706. doi: 10.1155/2015/ 323706

Wynn, T. A. (2007). Common and unique mechanisms regulate fibrosis in various fibroproliferative diseases. J. Clin. Invest. 117, 524-529. doi: 10.1172/JCI31 487

Xiao, L., and Liu, Y. (2013). Fibrosis and anaemia in CKD-two beasts, one ancestor. Nat. Rev. Nephrol. 9, 563-565. doi: 10.1038/nrneph.2013. 179

Xie, Y., Sul, N., Yang, J., Tan, Q., Huang, S., and Jin, M. (2020). FGF/FGFR signaling in health and disease. Signal Transduct. Target. Ther. 5:181. doi: 10.1038/s41392-020-00222-7

Xu, L., Yates, C. C., Lockyer, P., Xie, L., Bevilacqua, A., and He, J. (2014). MMI0100 inhibits cardiac fibrosis in myocardial infarction by direct actions on cardiomyocytes and fibroblasts via MK2 inhibition. J. Mol. Cell Cardiol. 77, 86-101. doi: 10.1016/j.yjmcc.2014.09.011
Yahiaoui, Y., Jablonski, M., Hubert, D., Mosnier-Pudar, H., Noël, LHl, and Stern, M. (2009). Renal Involvement in Cystic Fibrosis: diseases spectrum and clinical relevance. Clin. J. Am. Soc. Nephrol. 4, 921-928. doi: 10.2215/CJN.00750209

Yang, L., Kwon, J., Popov, Y., Gajdos, G. B., Ordog, T., and Brekken, R. A. (2014). Vascular endothelial growth factor promotes fibrosis resolution and repair in mice. Gastroenterology 146, 1339-1350.e1. doi: 10.1053/j.gastro.2014.01.061

Yang, L., Tian, L., Zhang, Z., Zhou, X., Ji, X., and Liu, F. (2020). “Cannabinoid Receptor 1/miR-30b-5p Axis Governs Macrophage NLRP3 Expression and Inflammasome Activation in Liver Inflammatory Disease. Mol. Ther. Nucleic Acids 20, 725-738. doi: 10.1016/j.omtn.2020.04.010

Yasuoka, H., Hsu, E., Ruiz, X. D., Steinman, R. A., Choi, A. M. K., and FeghaliBostwick, C. A. (2009). The fibrotic phenotype induced by IGFBP-5 is regulated by MAPK activation and Egr-1-dependent and -independent mechanisms. Am. J. Pathol. 175, 605-615. doi: 10.2353/ajpath.2009.080991

Yoshimatsu, Y., Wakabayashi, I., Kimuro, S., Takahashi, N., Takahashi, K., and Kobayashi, M. (2020). TNF- $\alpha$ enhances TGF- $\beta$-induced endothelial-tomesenchymal transition via TGF- $\beta$ signal augmentation. Cancer Sci. 111, 2385-2399. doi: 10.1111/cas.14455

Zahr, A. A., Salama, M. E., Carreau, N., Tremblay, D., Verstovsek, S., and Mesa, R. (2016). Bone marrow fibrosis in myelofibrosis: pathogenesis, prognosis and targeted strategies. Haematologica 101, 660-671. doi: 10.3324/haematol.2015. 141283

Zaman, T., and Lee, J. S. (2018). Risk Factors for the Development of Idiopathic Pulmonary Fibrosis: a Review. Curr. Pulmonol. Rep. 7, 118-125. doi: 10.1007/ s13665-018-0210-7

Ziring, D., Wei, B., Velazquez, P., Schrage, M., Buckley, N. E., and Braun, J. (2006). Formation of $\mathrm{B}$ and $\mathrm{T}$ cell subsets require the cannabinoid receptor CB2. Immunogenetics 58, 714-725. doi: 10.1007/s00251-006-0138- $\mathrm{x}$

Zurier, R. B., and Burstein, S. H. (2016). Cannabinoids, inflammation, and fibrosis. FASEB J. 30, 3682-3689. doi: 10.1096/fj.201600646R

Conflict of Interest: The authors declare that the research was conducted in the absence of any commercial or financial relationships that could be construed as a potential conflict of interest.

Publisher's Note: All claims expressed in this article are solely those of the authors and do not necessarily represent those of their affiliated organizations, or those of the publisher, the editors and the reviewers. Any product that may be evaluated in this article, or claim that may be made by its manufacturer, is not guaranteed or endorsed by the publisher.

Copyright (c) 2021 Pryimak, Zaiachuk, Kovalchuk and Kovalchuk. This is an openaccess article distributed under the terms of the Creative Commons Attribution License (CC BY). The use, distribution or reproduction in other forums is permitted, provided the original author(s) and the copyright owner(s) are credited and that the original publication in this journal is cited, in accordance with accepted academic practice. No use, distribution or reproduction is permitted which does not comply with these terms. 